\title{
New Genomic Approaches to Enhance Biomass Degradation by the Industrial Fungus Trichoderma reesei
}

\author{
Renato Graciano de Paula (D), Amanda Cristina Campos Antoniêto, \\ Liliane Fraga Costa Ribeiro, Cláudia Batista Carraro, Karoline Maria Vieira Nogueira, \\ Douglas Christian Borges Lopes $\mathbb{D}$, Alinne Costa Silva, Mariana Taíse Zerbini, \\ Wellington Ramos Pedersoli, Mariana do Nascimento Costa, and Roberto Nascimento Silva
}

\begin{abstract}
Molecular Biotechnology Laboratory, Department of Biochemistry and Immunology, Ribeirao Preto Medical School (FMRP), University of Sao Paulo, Ribeirao Preto, SP, Brazil
\end{abstract}

Correspondence should be addressed to Renato Graciano de Paula; renatogpaula@usp.br

Received 21 March 2018; Revised 20 June 2018; Accepted 29 July 2018; Published 24 September 2018

Academic Editor: Raul A. Platero

Copyright (c) 2018 Renato Graciano de Paula et al. This is an open access article distributed under the Creative Commons Attribution License, which permits unrestricted use, distribution, and reproduction in any medium, provided the original work is properly cited.

\begin{abstract}
The filamentous fungi Trichoderma reesei is one of the most well-studied cellulolytic microorganisms. It is the most important fungus for the industrial production of enzymes to biomass deconstruction being widely used in the biotechnology industry, mainly in the production of biofuels. Here, we performed an analytic review of the holocellulolytic system presented by $T$. reesei as well as the transcriptional and signaling mechanisms involved with holocellulase expression in this fungus. We also discuss new perspectives about control of secretion and cellulase expression based on RNA-seq and functional characterization data of $T$. reesei growth in different carbon sources, which comprise glucose, cellulose, sophorose, and sugarcane bagasse.
\end{abstract}

\section{Trichoderma reesei: Environmental and Lignocellulosic Biomass Degrader}

Trichoderma species are ubiquitous and cosmopolitan. They are very efficient colonizers of a variety of habitats and can be found from the tundra to the tropics [1], especially in lignocellulosic material and plant rhizospheres, and this effectiveness is translated by the ability of competently degrading the available substrate and of secreting different enzymes and metabolites used in the process [2-5]. The capability of growing in such a variety of carbon sources is also due to the high and fast capacity of responding to diverse environmental signals, being able to adapt according to that current background and regulate its growth, conidiation, and the production of enzymes and secondary metabolites. These signals may vary from different nutrients found in the milieu to the absence and presence of light, and adjusting to them is crucial for the survival of the microorganism $[2,4,6-8]$.
As a result of this versatility, Trichoderma species are very useful in many aspects that range from plant biocontrol [9] to various sorts of industries [10-13], especially for the cellulolytic enzymes produced by them. Among all species from this genus and which are industrially used, Trichoderma reesei is the most studied one regarding lignocellulosic biomass degradation, since it is the main producer of cellulolytic and xylanolytic enzymes [14-17]. The ability of growing in a wide range of carbon sources allows great variability in the production of cellulases, since the gene expression and secretion of enzymes are directly dependent on the different chemical signals produced from the diverse substrates. Considering that the plant biomass, one of the most important and complex substrates used by Trichoderma, is composed of mono-, di-, and polysaccharides, the different sugars may have different levels of induction or repression of cellulase genes. Some of the cellulase inducers are cellulose, $\beta$-glucan, xylan, lactose, cellobiose, and sophorose, while glucose is the main repressor carbon source [18]. When T. reesei degrades 


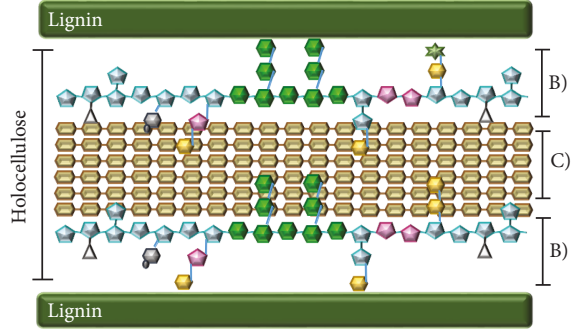

(a)

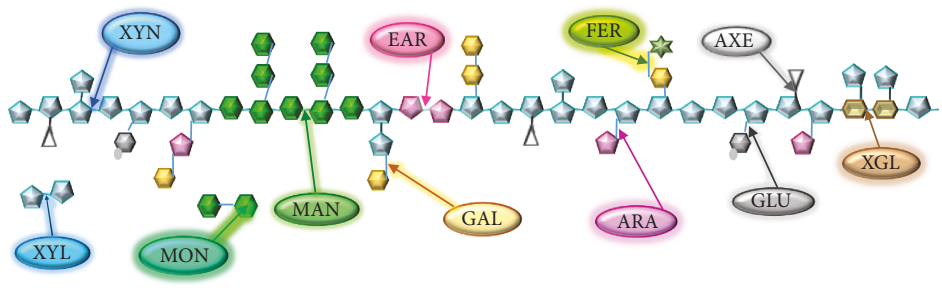

(b) Hemicellulose
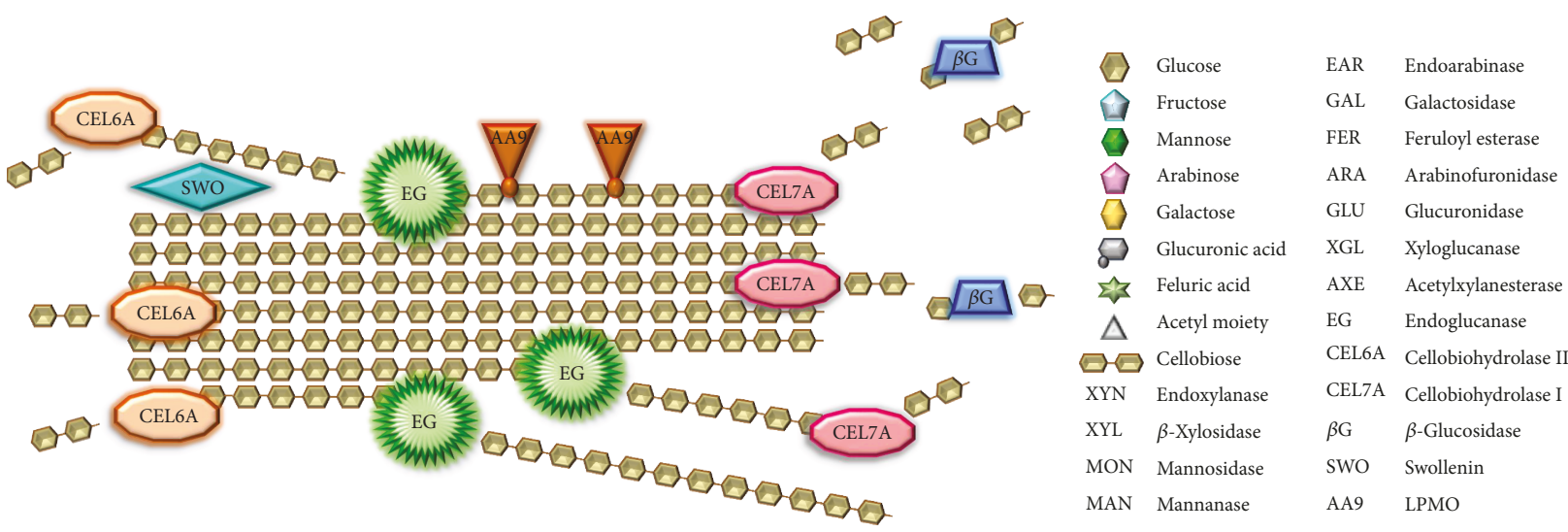

(c) Cellulose

Figure 1: Global regulation of holocellulase expression in T. reesei. (a) The schematic structure of the lignocellulosic biomass, which is constituted by lignin and holocellulose, composed of hemicellulose and cellulose. All chains are drawn from the reducing (left) to the nonreducing end (right). (b) Enzymes that attack hemicellulose act in synergy in order to efficiently hydrolyze it and promote a more accessible surface area on cellulose, to enhance cellulase activities. (c) The enzymatic degradation of cellulose: EG acts by cleaving in amorphous regions of the chain, while CEL6A and CEL7A cleave at the nonreducing and reducing ends, respectively. The resulting oligosaccharides from this cleavage are then broken into monosaccharides by $\beta$-glucosidase, so they become capable of being directly metabolized by the organism. SWO expands the cellulolytic chain to improve cellulase accessibility to it, and AA9 works through bivalentmetallic-ion-dependent oxidative metabolism (based, among others, on [39, 144-146]).

the lignocellulosic biomass, cellobiose may be converted into sophorose by a transglycosylation activity of a $\beta$-glucosidase $[19,20]$. The comparison of the genomes of Trichoderma species, including $T$. reese $i$, suggests they have a mycoparasitic common ancestral, probably from fungi that degrade lignocellulosic material. Considering this, T. reesei may have maintained the mycoparasitic characteristic, which allows it to have advantages over other species when competing for substrate, through the conversion of cellobiose into sophorose by transglycosylation to be metabolized $[21,22]$. Differently from other fungi, in T. reesei, sophorose acts as a very potent cellulase inducer in very low concentrations, being able to induce the expression of some xylanases as well $[23,24]$.

With the increasing concern about the environmental disadvantages that fossil fuels and nuclear energy represent nowadays, there has been considerable pursuit for new ways of generating large-scale renewable green energy. One of the currently most promising possibilities is the usage of lignocellulosic material from agricultural and industrial waste $[25,26]$. This material is mainly composed of cellulose and hemicellulose, which suffer enzymatic hydrolysis and are converted into simple carbohydrate monomers and finally into second-generation bioethanol [13, 27, 28]. However, considering that the plant biomass is highly recalcitrant, large amounts of enzymes are needed during the hydrolysis process, which make the biofuel production economically unfeasible [29-31]. In this context, Trichoderma reesei may play an important role in decreasing costs for bioethanol production, whereas it is the filamentous fungus with the greatest capacity of degrading the lignocellulosic biomass $[2,15,32]$.

\section{The Global Analysis of the Enzymatic Repertoire of Trichoderma reesei}

The filamentous fungus $T$. reesei obtains energy through the degradation of the lignocellulosic biomass, composed specially of the cellulose polymer $[2,33,34]$. The cellulolytic enzymes synergistically act to degrade the cellulose polymer. Regarding the site of action, these enzymes are classified in at least three large groups: the endoglucanases, which cleave the internal bonds of the cellulose fiber; the exoglucanases, which act in the external region of the cellulose chain; and $\beta$-glucosidases, which hydrolyze soluble oligosaccharides into glucose molecules [2, 35] (Figure 1). Recently, LPMOs (lytic 
polysaccharide monooxygenases) have been suggested to make the cellulose polymer more accessible to the action of traditional cellulases through an oxidative mechanism [36]. In addition to the LPMOs, a protein known as swollenin also participates in the deconstruction of the plant cell wall by breaking the hydrogen bonds between the cellulose microfibrils without hydrolyzing them, thus increasing the biomass degradation efficiency [37] (Figure 1).

In 2012, Häkkinen and coworkers performed a reannotation of all genes encoding enzymes belonging to CAZy (Carbohydrate-Active Enzymes-http://www.cazy.org) in T. reesei and identified 201 genes of glycosyl hydrolases, 22 carbohydrate esterases, and 5 genes of polysaccharide lyases [38]. The cellulases produced by $T$. reesei belong to six $\mathrm{GH}$ families: endo- $\beta$-1,4-D-glucanases are found in the GH5, GH7, GH12, and GH45 families, the exoglucanases in the GH6 and GH7 families, and the $\beta$-glucosidases in the family GH3 [39]. The Cel7a is the dominant enzyme of the cellulolytic complex, comprising about $60 \%$ of the total proteins secreted by T. reesei, followed by Cel6a (20\%), and then the endoglucanases, mostly Cel7b (10\%). In fewer amounts, the $\beta$-glucosidases represent only $1 \%$ of the total proteins secreted by this species [40-42].

In 2014, dos Santos Castro and coworkers showed that when $T$. reese $i$ is grown in cellulase inducing carbon sources, such as cellulose and sophorose, CAZyme-encoding genes are highly transcriptionally induced. An opposite profile is observed during growth in glucose, in which most of the genes encoding $\mathrm{GH}$ families had low expression. In this study, 61 genes encoding CAZymes were highly expressed in the presence of cellulose in comparison to glucose [21]. Among these, the main gene upregulated was a copperdependent polysaccharide monooxygenase cel61b (ID 120961), almost 3 thousand-fold more expressed in cellulose than in glucose. The endoglucanase cel12a (ID 123232) was the second most upregulated gene in this condition, followed by a $\beta$-mannanase. In sophorose, 58 genes were transcriptionally induced when compared to glucose. The most expressed gene in this condition was the endoglucanase cel12a (ID 123232, as well as observed in cellulose). The two cellobiohydrolases of $T$. reesei cel7a (ID 123989) and cel6a (ID 72567) ranked the second and third among the most expressed genes in sophorose [21] (Figure 2). In a study by de Paula [43], 98 CAZyme-encoding genes were upregulated during growth in sugarcane bagasse compared to glycerol in the $T$. reesei QM6a strain. The endoglucanase cel12a was the third most expressed gene in this condition, similar to that found by dos Santos Castro and coworkers [21] in the presence of cellulose. The two CAZyme genes most expressed in sugarcane bagasse encode a mannanase from the GH76 family (ID 122495) and the hemicellulase xyn3 (ID 120229). Similar to that found by dos Santos Castro and coworkers in sophorose [21], the cellobiohydrolase cel7a was also highly expressed in sugarcane bagasse, achieving 326-fold higher expression in sugarcane bagasse than in glycerol (ID 122495) (Figure 2).

CAZyme gene expression is regulated at the transcriptional level by transcription factors such as XYR1 and CRE1 (for more details, see Transcriptional Regulation of
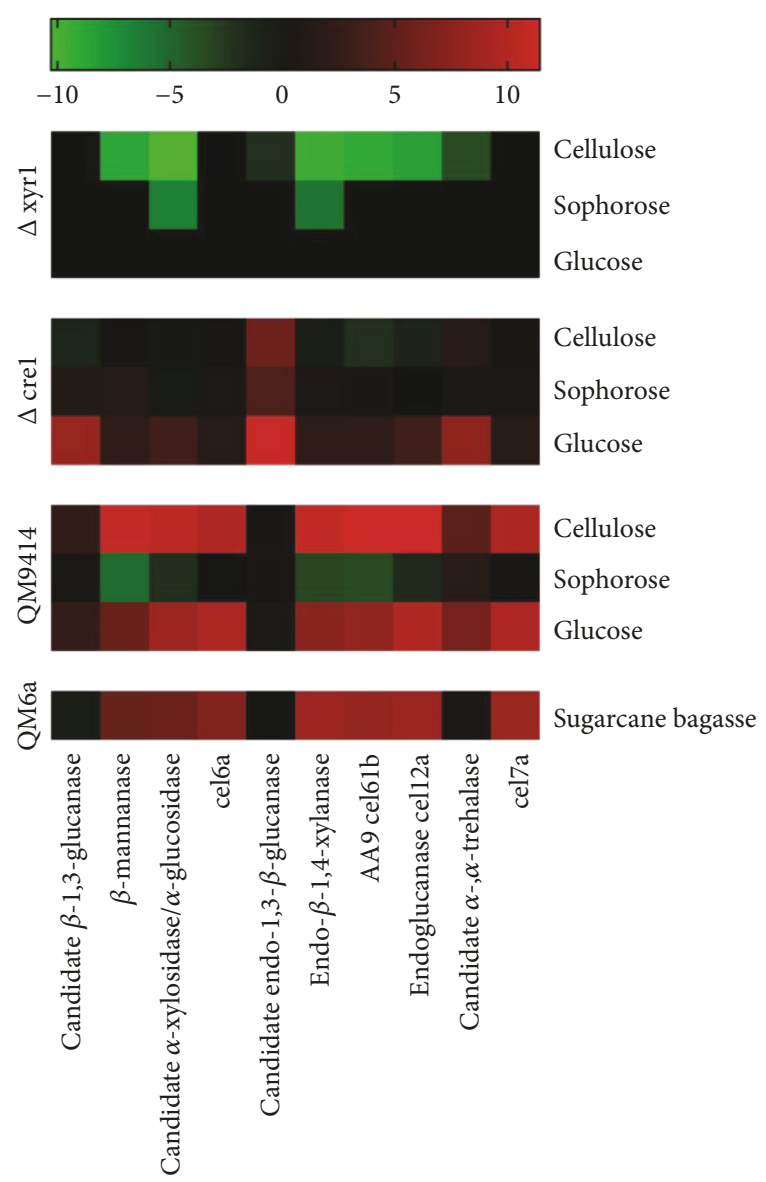

FIgURE 2: Heatmap expression of Top CAZy-encoding genes differentially expressed in $T$. reesei strains grown in cellulose, sophorose, glucose, and sugarcane bagasse. The results of gene expressions were transformed in Log2FoldChange values and employed to heat map construction using the GraphPad Prism version 7 program (https://www.graphpad.com/).

Biomass Degradation). In 2016, dos Santos Castro and coworkers showed that the XYR1 regulator positively regulates expression of at least 61 CAZyme genes in cellulose and 46 genes in sophorose [35]. The genes encoding a candidate $\alpha$-xylosidase $/ \alpha$-glucosidase (ID 69944), endo- $\beta$ 1,4-xylanase (ID 120229), and a copper-dependent monooxygenase polysaccharide candidate AA9 (ID 120961) were the major XYR1 target in the presence of cellulose. All of them were more than 500-fold less expressed in the $\Delta x y r 1$ mutant compared to the parental QM9414, and the first two genes were also modulated by XYR1 in the presence of sophorose. However, none of these genes are under CRE1-mediated carbon catabolic repression (CCR) [44, 45] (Figure 2). CRE1-mediated CCR was also evaluated regarding the CAZymes of T. reesei by Antoniêto and coworkers [44, 45]. In these studies, the most evident CCR occurred during growth of T. reesei in glucose [45]. In this condition, several genes encoding CAZymes were repressed by CRE1. A gene encoding a candidate endo-1,3- $\beta$-glucanase (ID 73256) was the most repressed by CRE1, being more than 2 thousandfold more expressed in the mutant $\Delta c r e 1$ compared to the QM9414, followed by another candidate $\beta$-1,3-glucanase 
(ID 56418) and a candidate $\alpha, \alpha$-trehalase (ID 123456) (Figure 2). The trehalase gene was also under positive regulation of XYR1 [35]. Modulation of the trehalase gene by the XYR1 and CRE1 regulators may be a strategy adopted by $T$. reesei to avoid the unnecessary use of the energy stock when a readily available carbon source is in the culture medium, since this disaccharide acts as an energetic reserve in fungi [44]. Taken together, these results showed that, although the cellulase gene expression profile is similar during $T$. reesei growth in inducing carbon sources such as cellulose, sophorose, and sugarcane bagasse, the mechanisms employed by XYR1 and CRE1 to control the expression of specific genes are dependent on the carbon source available in the environment (Figure 2).

\section{Involvement of Transporters during the Lignocellulosic Biomass Degradation Process in Trichoderma reesei}

The process of lignocellulosic biomass utilization involves the capacity of $T$. reesei to sense the insoluble cellulose in the environment and initiates the rapid production of the enzymatic machinery required to breakdown cellulose and offer the nutrients to its growth [46-48]. Appropriated sense of the extracellular insoluble cellulose is key to initiating the rapid synthesis of cellulases by this fungus, and the uptake of soluble sugars released from biomass hydrolysis denote a potential point of control in the induced cascade [48]. In this context, transporter proteins have an important role during the biomass degradation process. Transport systems act in the sensing and uptaking of essential nutrients and ions, allowing excretion of end products of metabolism and toxic substances. Also, these transporters are involved in communication between cells and the environment $[49,50]$. It is possible that organisms sense cellulose through recognition of sugars by a transporter in the membrane. In fact, two MFS sugar transporters, Stp1 and Crt1, were implicated in cellulose sensing and cellulase induction in T. reesei [48]. Transporter proteins can carry different small molecule inducers from the extracellular environment into the fungus influencing the expression of CAZyme-encoding genes [51-53]. Approximately, 5\% (459 genes) of the T. reesei genome comprises genes that encode proteins involved in transport [21]. Among these, the largest group of identified transporters belongs to the major facilitator superfamily (MFS), class of sugar transporters, followed by ABC (ATP binding cassette) transporters. These two families of transporter proteins have been most intensively studied among the fungal transporters $[34,54]$.

The genomes of the filamentous fungus encode large numbers of MFS transporters $[55,56]$. These proteins can transport a broad variety of substrates and are divided into 17 distinct families among which three families $(1,5$, and 7$)$ are involved in sugar transport into the cell. These transporters carried out the transport of carbon sources, including hexose and pentose sugars, and small soluble molecules in response to ion gradients $[50,57,58]$. In the filamentous fungus, sugar transporters, which belong to the MFS permease family, have a characteristic to recognize and carry more than one type of sugar into the fungal cell. For example, the $T$. reesei STP1 transporter is involved in glucose and cellobiose uptake [48], as well as Aspergillus nidulans transporter XtrD was shown to be able to transport xylose, glucose, and several other monosaccharides [59].

Despite advances in studies about the involvement of MFS sugar transporters during biomass degradation, a very few sugar transporters have been functionally characterized in $T$. reesei $[48,60,61]$. A deep transcriptomic and proteomic study investigating the molecular basis for lignocellulosedegrading enzyme production in $T$. reesei during growth in cellulose, sophorose, and glucose revealed new components involved in cellulose degradation, including transporters, while the MFS permeases family was the most present in the different carbon sources evaluated [21]. In this study, MFS permeases differentially expressed in the three carbon sources were analyzed. The gene encoding MFS permease (ID 69957) and MFS permease (ID 76800), targets of light signaling in Trichoderma, were highly expressed in cellulose when compared to glucose and sophorose. In sophorose, a gene encoding MFS maltose permease (ID 48444) was highly induced by this carbon source, while the MFS permease ID 76641 was expressed at a higher level in glucose than in sophorose or cellulose [21]. Conversely, cultures with cellulose or sophorose promoted the expression of MFS permeases at similar expression levels, including crt1 (ID 3405), required for cellulase induction by cellulose and lactose, besides mediating the cellulose sensing process in $T$. reesei [48]; Hxt1, a glucose permease [60]; Str1 (ID 50894), a xylose transporter [61]; and MFS ID 79202, which is critical for cellulase production in lactose cultures, although it is related to a sucrose transporter. In addition, the stp1 exhibited a higher level of expression in sophorose than in cellulose, although it is involved in cellobiose and glucose transport [21].

In addition, in T. reesei, the global induction of genes in response to exposure to wheat straw showed that MFS transporters were highly transcribed in straw and repressed in glucose-rich conditions. The genes encoding MFS ID 3405 (crt1), ID 50894 (str1), and ID 69957 were upregulated in the presence of straw and downregulated in the presence of glucose [62]. Besides, during cultivation of T. reesei RUT C30 strain in sugarcane bagasse, the genes encoding the MFS permeases ctrl and strl were strongly induced by this carbon source at all the time points analyzed $(6,12$, and 24 hours) [63]. The induction of MFS transporters may be controlled by endogenous regulatory systems over a range of in vivo conditions. In $T$. reesei, the modulation of transporter expression was shown to be carbon sourcedependent [21, 35, 44]. A global transcriptome analysis of the $\Delta x y r 1 T$. reesei mutant strain and the parental strain QM9414 grown in the presence of cellulose, sophorose, and glucose as sole carbon sources showed that genes encoding to proteins belonging to MFS permease superfamily are the most modulated genes by XYR1 (Figure 3). The genes that encode a MFS permease ID 69957, ID 44175, ID 54632, ID 79202, ID 50894, and the ctrl showed to be strongly repressed by XYR1 in the presence of cellulose [35]. 


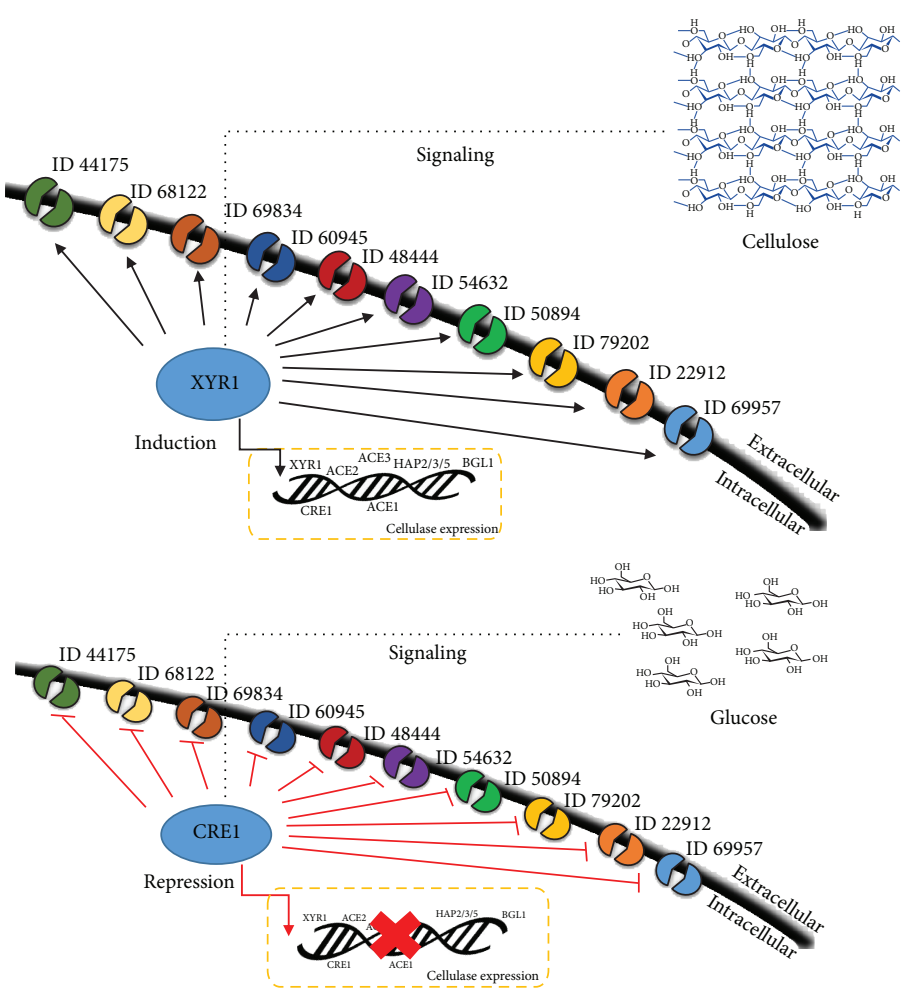

(a)

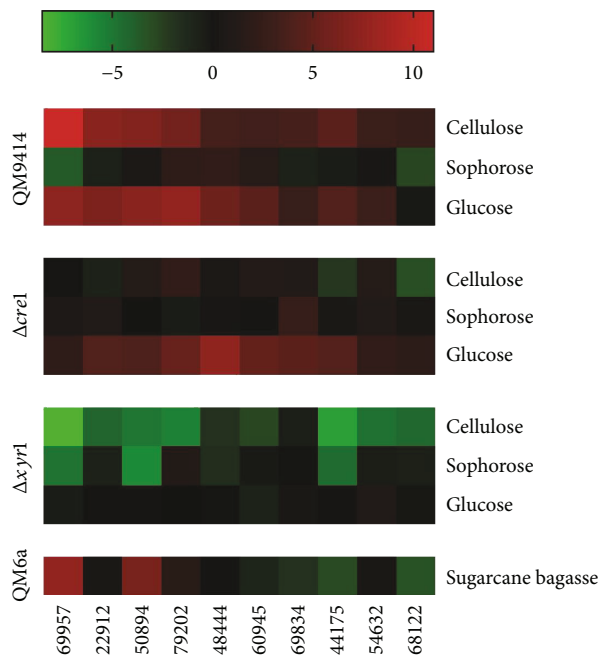

(b)

FIGURE 3: Sugar transporters potentially associated with the degradation of biomass in T. reesei. (a) The predicted model of XYR1 and CRE1mediated MFS permease regulation in T. reesei under cellulose inducing condition and glucose repressed condition. (b) Heatmap expression of Top MFS transporter-encoding genes differentially expressed in T. reesei strains grown in cellulose, sophorose, glucose, and sugarcane bagasse. The results of gene expressions were transformed in Log2FoldChange values and employed to heat map construction using the GraphPad Prism version 7 program (https://www.graphpad.com/).

Furthermore, it is possible that the protein transporters are involved in carbon catabolic repression (CCR) in T. reesei. During analysis between $\Delta c r e 1 T$. reesei mutant strain and parental strain QM9414, grown in cellulose, glucose, and sophorose, the main genes marked by CRE1-mediated CCR encode to proteins belonging to MFS permeases superfamily. Most genes of MFS permeases were upregulated by CRE1 in the presence of glucose. Among these, the expression of the maltose permease gene (ID 48444) and three other MFS permease genes (ID 60945, ID 79202, and ID 44174) was higher in the $\Delta$ cre1 mutant than in the parental strain [45] (Figure 3). In sophorose, the gene encoding a xylose transporter gene (ID 104072) was highly repressed by CRE1. During the transcriptional analysis of $T$. reesei grown in wheat straw and glucose, this gene was strongly transcribed in wheat straw and repressed in glucose [62].

Furthermore, a large number of $\mathrm{ABC}$ transporters are encoded in T. reesei [34]. Generally, ABC proteins are integral to the membrane, acting as ATP-driven transporters for several substrates, including lipids, sugar, drugs, heavy metals, and auxin [64]. In fungi, ABC transporters are involved with the secretion of secondary metabolites, resistance to toxic compounds, and cell signaling [63]. Although the $\mathrm{ABC}$ transporters have been shown to be important for different processes in fungi, the role of the transporters belonging to the ABC family is still unclear in $T$. reesei. In this fungus, the $\mathrm{ABC}$ transporters showed carbon source-dependent transcriptional regulation, which were upregulated in cellulose and sophorose [35]. In cellulose, the ABC transporter ID 76682 was highly upregulated, while the gene encoding the ABC transporter ID 80028 was upregulated in sophorose [21]. Additionally, in T. reesei, it was demonstrated that the transport of molecules by $\mathrm{ABC}$ transporters is highly induced by wheat straw and lactose than glucose $[53,65]$.

The ABC transporters showed to be modulated by transcription factors such as XYR1 and CRE1. In $\Delta x y r 1$ $T$. reesei mutant strain, the genes encoding $\mathrm{ABC}$ transporters ID 55814, ID 60116 (MRP-type ABC transporter), and ID 120114 were downregulated in the presence of cellulose, sophorose, and glucose, respectively. Oppositely, the gene encoding ABC transporter ID 58899 (MDR-type $\mathrm{ABC}$ transporter) was upregulated in the presence of cellulose [35]. In $\Delta c r e 1$ mutant strain, the gene encoding ABC transporter ID 76682 (PDR-type ABC transporter) was upregulated in the presence of cellulose [45] while in sophorose, the major CRE1 repressed gene was ID 76682. However, four other ABC transporter genes (ID 82105, 123293,73924 , and 58899) were repressed by CRE1 in the presence of this carbon source [44]. Among the identified $\mathrm{ABC}$ transporters, most of them are correlated with multidrug resistance (MDR), pleiotropic drug resistance (PDR), and multidrug resistance-related protein (MRP) ABC protein subfamilies [66]. Although the ABC transporters 
contribute to multidrug resistance in microbial pathogens and tumor cells, in fungi, these transporters have been scarcely studied [34]. In other fungi, the ABC transporters are also related with mycoparasitic interaction and antifungal resistance $[67,68]$, and interestingly, several studies have shown the involvement of $\mathrm{ABC}$ transporters with the sugar transport [69]. For example, Sulfolobus solfataricus (extreme thermoacidophilic archaeon) uses several sugars as the sole carbon and energy source. This sugar transport is mediated by two families of protein binding dependent $\mathrm{ABC}$ transporters that may transport different sugars such as arabinose, cellobiose, maltose, and trehalose [70]. In Clorynebacterium glutamicum, Watanabe et al. [71] described a functional characterization of a xyloside $\mathrm{ABC}$ transporter and an enhanced uptake of xylooligosaccharides in the presence of a functional xylEFG-encoded xyloside ABC transporter. In Pyrococcus furiosus, cellobiose uptake involves an inducible $\mathrm{ABC}$ transporter system that not only binds cellobiose but also binds cellotriose, cellotetraose, cellopentaose, laminaribiose, laminaritriose, and sophorose [72].

As exposed here, both MFS transporters and $\mathrm{ABC}$ transporters are suggested to be involved during the process of biomass degradation in $T$. reesei. The novel transporters identified offer new perspectives for studies about the involvement of protein transporters in the expression and secretion of cellulase for degradation of lignocellulosic biomass. With this, new proteins might be revealed as involved in the process to sense and transduce signals related to biomass deconstruction, providing future strain improvement for cellulase production. The characterization of these transporters may allow the construction of more efficient strains in the degradation of plant biomass and contribute to the implementation of $T$. reese $i$ in the bioethanol industry.

\section{Transcriptional Regulation of Biomass Degradation}

The regulation of holocellulose degradation by the fungus $T$. reesei is a highly coordinated phenomenon dependent on the carbon sources available in the medium. In the presence of readily metabolizable carbon sources, such as glucose, the fungus represses the genes accountable for the expression of cellulolytic enzymes as a way of saving energy, while in the presence of inductive carbon sources, such as cellobiose and sophorose, the fungus activates the cellulase production. At the transcriptional level, transcription factors are the key proteins for regulating the expression of genes that act on the hydrolysis of the cellulose polymer [32, 73-75]. In T. reesei, ten transcription factors involved in the regulation of this process have been identified so far. They are the positive regulators XYR1, ACEII, ACEIII, LAE1, VEL1, BglR, and the HAP2/3/5 complex, as well the repressors ACEI, RCE1, and CRE1 (Figure 4).

In $T$. reesei, the XYR1 is the master positive regulator of cellulase production, and deletion of this transcription factor totally eliminates the cellulase gene expression and also impairs the induction of hemicellulolytic genes involved with the degradation of xylans and arabinans [73, 76-78]. In 2016, dos Santos Castro and coworkers showed that XYR1 mainly regulates genes belonging to the CAZymes family, in a carbon source-dependent manner [35]. In this work, two xylosidases were the main downregulated genes in the $\Delta x y r 1$ mutant in the presence of cellulose (ID 69944; 1260 -fold) and sophorose (ID 121127; 209-fold). In addition to CAZymes, transcription factors and transporters were also regulated by XYR1. Besides XYR1, the deletion of the aceII transcription factor causes a decrease in the transcription levels of most cellulases and significantly reduces the cellulolytic activity when the fungus is grown in a cellulosecontaining medium [79]. Furthermore, the ACEIII transcription factor was more recently discovered, and its deletion was detrimental to the production of cellulases and xylanases in T. reesei [80]. It is believed that the HAP2/3/5 complex promotes the formation of an open chromatin structure, necessary for the activation of the transcription process [81]. In addition, the BglR transcription factor acts as a positive regulator of $\beta$-glycosidases-specific genes [82]. Deletion of the lae 1 reduces the production of cellulases, xylanases, and the auxiliary factors CIP1 and swollenin [83]. Finally, deletion of vell completely decreases the expression of cellulases, xylanases, and xyr1 genes in the presence of lactose. Interestingly, studies have shown that a combined action occurs between the LAE1/VEL1 complex for regulation of genes involved in biomass degradation $[83,84]$.

Among the negative regulators of cellulase gene transcription, the main transcription factor is the CRE1 catabolic repressor [75]. In 2014, Antoniêto et al. showed that, in addition to traditional cellulases, CRE1 deletion affects the expression of genes involved in nutrient transport, other transcription factors, and oxidative metabolism. In the presence of cellulose, this regulator represses genes encoding copper transporters and ferric reductase enzymes and, consequently, inhibits the access of the traditional cellulases to the cellulose polymer. In the presence of glucose, CRE1 acts suppressing the expression of genes related to the entry of the inducers into the cell [45]. It was also shown that the transcription factor xyrl (ID 122208) is the main target regulator of CRE1 in the presence of glucose, being almost 40 times more expressed in the mutant $\Delta$ crel when compared to the parental QM9414 [45]. In sophorose, CRE1 mainly modulates CAZYmes and membrane permeases, including maltose permeases that possibly act transporting the disaccharide sophorose [44]. Regarding the other negative regulators of cellulose degradation, studies have shown that ACEI represses the expression of the major cellulolytic genes (cbh1, cbh2, egl1, and egl2) and xylanases (xyn1 and xyn2), under the cellulose- and sophorose-inducing conditions [85]. In 2017, Cao and coworkers identified a new transcription factor, Rcel, which acts as a repressor of cellulase gene expression, antagonizing XYR1 by binding to the $c b h 1$ promoter [86].

Despite the numerous studies about the transcription factors already identified in $T$. reesei, several regulatory proteins involved in the regulation of the lignocellulosic biomass deconstruction have not been characterized yet (Figure 4). In a study of dos Santos Castro and coworkers [21], the expression of 7 genes encoding transcription factors was affected during growth in cellulose. Likewise, 18 genes 

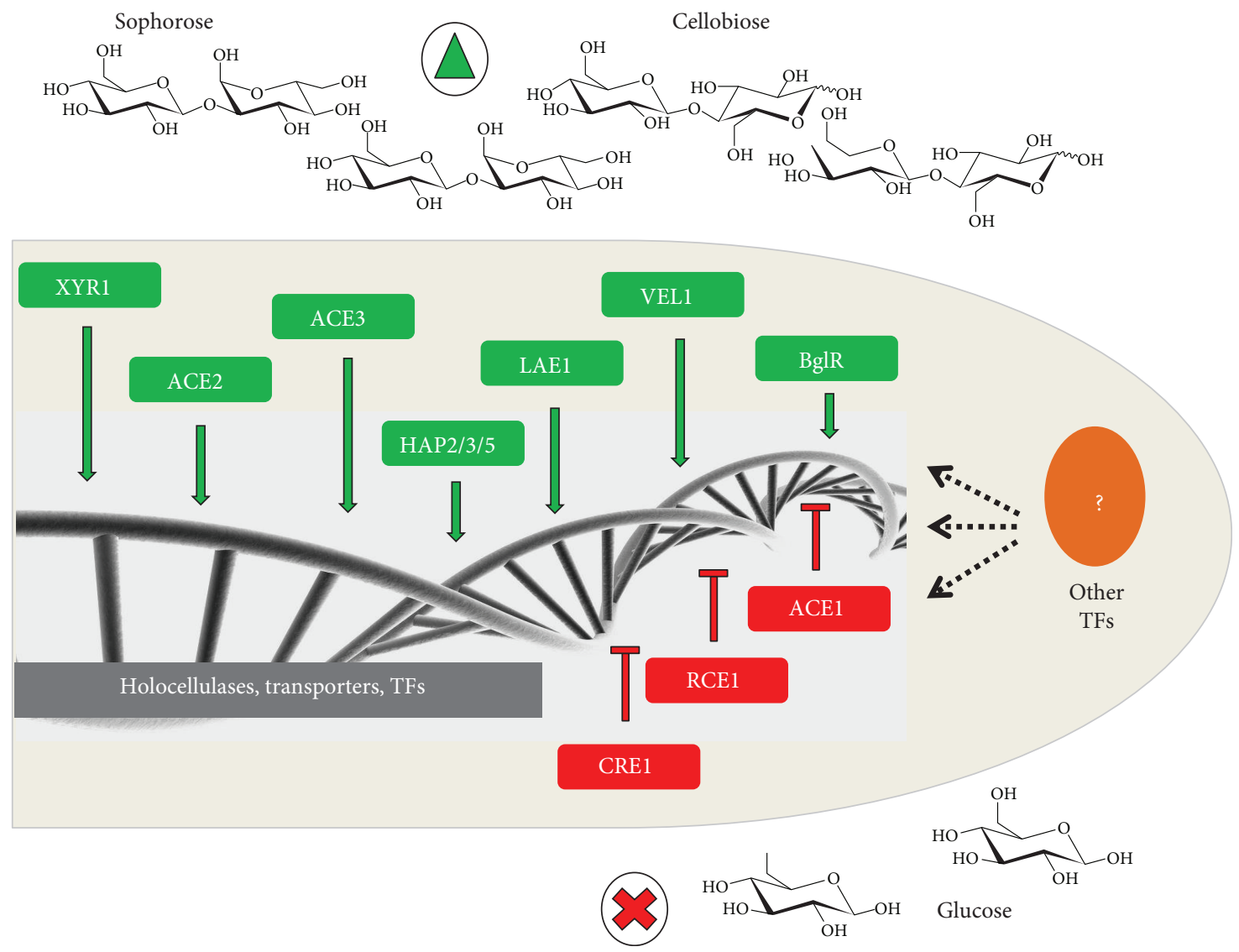

Figure 4: Overview of the transcriptional regulation of biomass degradation. The regulation of cellulose deconstruction involves at least 10 transcription factors: the positive regulators XYR1, ACEII, ACEIII, LAE1, VEL1, BglR, and the HAP2/3/5 complex, as well the repressors ACEI, RCE1, and CRE1. However, several transcription factors still not identified are potentially involved in this mechanism.

were also modulated in the presence of sophorose and glucose. In sugarcane bagasse, 88 transcription factors were modulated in the QM6a strain compared to the growth in glycerol [43]. Expression of several genes encoding transcription factors was also under regulation of XYR1 and CRE1. During cultivation in cellulose and glucose, 14 transcription factors were targeted by the CRE1-mediated mechanism of carbon catabolic repression (CCR) [45]. In sophorose, 8 regulators were also regulated by CRE1 [44]. The main positive regulator of cellulase production, XYR1, regulates the expression of other 31 transcription factors in the presence of cellulose, 17 in sophorose, and 7 in glucose [35]. In all these studies, most of the transcription factors modulated have not been characterized yet, which highlights the importance of exploring more about the regulatory proteins involved in the degradation of biomass.

\section{Epigenetic Regulation of Holocellulase Expression}

Another important mechanism of gene transcriptional regulation involves the chromatin modification, a phenomenon that includes the modification of the histones which are the proteins responsible for the DNA packaging. In T. reesei, the evidence of nucleosome rearrangement in the promoter region of cel6a and cel7a suggests that chromatin remodeling is necessary to promote cellulolytic enzyme expression [81, 87]. Interestingly, deleting the methyltransferase LAE1 impairs cellulase expression, while overexpressing this protein increases cellulase expression and changes in the H3K4 methylation pattern in the promoter region of cel5b [83]. This mechanism of regulation was also demonstrated in $M$. oryzae, in which deleting the methyltransferase MoSET1 decreased cellulase induction [88]. Likewise, acetyltransferases are important enzymes involved with chromatin remodeling. In $T$. reese $i$, acetyltransferases belonging to the GCN5 family are crucial for cellulase expression [89]. During growth of the T. reesei QM6a in sugarcane bagasse, de Paula [43] showed that at least 9 genes related to chromatin remodeling were upregulated and 8 downregulated in comparison to glycerol. Of these genes, the acetyltransferase SidF (ID 82628) was almost 40 times more expressed in sugarcane bagasse, reaching the top of the list of genes modulated by this carbon source [43]. Also, dos Santos Castro and coworkers showed that two genes encoding a SWI-SNF chromatin-remodeling complex protein (ID 123327 and ID 122943) were also highly expressed in the presence of cellulose and sophorose [21]. This last gene was a target of CCR by CRE1 under cellulose condition [45]. All these findings reinforce the evidence of the involvement of the chromatin modifications in the mechanism of biomass degradation by the filamentous fungus T. reesei. 
The genetic engineering has become an important way for improving the production of holocellulolytic enzymes. The modification of gene promoters has also been extensively studied. Recently, Hirasawa and coworkers modified the promoter region of $x y n 3$ by using the $x y n 1$ cis-acting region and obtained improved enzyme expression [90]. A study of Zou and coworkers also showed that the CRE1 binding motifs in the promoter region of $c b h 1$ were replaced by the binding motifs of the positive regulators ACEII and the HAP2/3/5 complex, thus improving the promoter efficiency [91]. In addition, Uzbas and coworkers obtained a $\Delta x y r 1$ strain able to secrete the cellulases cel7a, cel7b, and cel12a under control of the promoter regions of two highly expressed genes tef1 and cdnal in a glucose-containing medium [92]. Similarly, the CCR in the presence of glucose was also eliminated by the deletion of CRE1 binding sites and insertion of multiple copies of positive regulator-binding sites in the promoter region of $c b h 1$, also increasing the heterologous gene expression in T. reesei [93]. These reports highlight the importance of investigating the transcription factors involved in the regulation of biomass degradation and the mechanisms through which these regulators interact with the architectural framework of the DNA in order to improve the holocellulase production.

\section{Signaling Pathways Involved in Cellulose, Sophorose, Glucose, and Sugarcane Bagasse Recognition}

The sensing of the changing environment is an important event for both survival and fungi competition. The fungi have appreciated mechanisms involved in sending signals and reacting to them $[34,94,95]$. Right after the perception of environmental signals, a complex network can be initiated, which is responsible for integrating all signals and promoting a suitable gene response to desirably react to the environment conditions [34]. In $T$. reesei, different signaling pathways have been described to be involved with fungal development and environment sensing. Among these, the signaling pathways dependent on G protein, cAMP, Ras-GTPases, protein kinases, phosphatases, calcium, and MAPK are the mostly characterized intracellular pathways although some aspects remain unclear [95-104]. Several studies showed the involvement of $\mathrm{G} \alpha$ proteins in the regulation of cellulase gene transcription by light $[105,106]$. A functional characterization of a GPCR-encoding gene of Trichoderma atrovoviride showed its role in vegetative growth and conidiation [107] and expression of chitinase-encoding genes [108]. Recently, it was demonstrated that two $G$ proteins $G \beta$ and $G \gamma$ s act along with a class I phosducin protein controlling the expression of glycoside hydrolase genes [109]. The cAMP pathway is a highly conserved signaling cascade in which cAMP acts as secondary messenger promoting the integration of different pathways [99]. In T. reesei, cAMP levels control cellulase gene expression [110] and according to Nogueira et al. [111], this regulation is in a carbon source-dependent manner.

The cellulase gene expression can also be regulated by the dynamics of protein phosphorylation and dephosphorylation involving protein kinases and phosphatases [34], respectively. Schuster et al. [112] demonstrated the role of protein kinase A (PKA) in the regulation of cellulase expression in the presence of light. Additionally, the deletion of a T. reesei casein kinase II promotes the decrease of chitinase expression and repression of sporulation and glucose metabolism [113]. Similarly, $\mathrm{He}$ et al. [114] showed that the deletion of protein kinase EKil increases the chitinase-encoding gene expression, radial growth, conidiation, and ethanolamine accumulation in the cell wall. The MAPK-mediated phosphorylation can regulate important processes in $T$. reesei. The deletion of the MAPK gene tmk3 induced a decrease in transcription and cellulase production [115]. Furthermore, it was also demonstrated that $t m k 2$ is involved in processes regulating cell wall integrity, sporulation and, cellulase production [116]. Recently, it was shown that MAPK IME2 represses the expression of the three main cellulase genes (cbh1, cbh2, and egl1) in $T$. reesei as well as activates the XYR1 and CRE1 expressions [117].

Finally, another interesting signaling cascade involved with the regulation of important processes in fungi is the intracellular calcium-dependent signaling pathway. The calcium homeostasis is essential for organisms, and its intracellular level reflects the environmental changes [118, 119]. In $T$. reesei, calcium-modulated protein (calmodulin) has an important role in xylanase expression [120]. Equally, it was demonstrated that NCS (neuronal calcium sensor-like) interacts with calcineurin and phosphodiesterase, regulating the light-dependent signaling pathway involved with the control of cellulase expression [121]. Recent reports have shown the differential expression of genes encoding calcium transporters and other calcium signaling pathway members during cultivation of $T$. reesei QM9414, $\Delta x y r 1 \mathrm{e}$ $\Delta$ cre 1 strains in the presence of cellulose, sophorose, and glucose $[21,35,44,45]$. Similarly, the cultivation of $T$. reese $i$ QM6a strain in sugarcane bagasse, glucose, and glycerol induced the expression of genes encoding $\mathrm{Ca}^{2+}$-ATPases and other calcium signaling transporters [43]. These results suggest the involvement of different signaling pathways controlling cellulase expression in the filamentous fungus $T$. reesei.

A deep analysis of gene expression in two functional mutant strains of main transcription factors (XYR1 and CRE1) [35, 44, 45] and two MAPK-encoding genes showed that different signaling pathways and regulatory mechanisms are involved with the regulation of cellulase expression [43]. The main finding of these studies was that the enzyme regulation is carbon source-dependent. The growth of the QM9414 parental strain in the presence of cellulose and sophorose revealed a distinct expression pattern of genes encoding proteins involved with intracellular signaling. Additionally, 50 and 28 genes related to signal transduction were differentially expressed in the presence of cellulose and sophorose, respectively [35]. In cellulose, the main upregulated gene encoded to a conidiospore surface protein cmp1 (ID 72379), which was 21 -fold more expressed in the parental strain. Oppositely, the most upregulated gene in sophorose encoded to an unknown protein (ID 73119), which was 8 -fold more in the parental strain. Regarding 


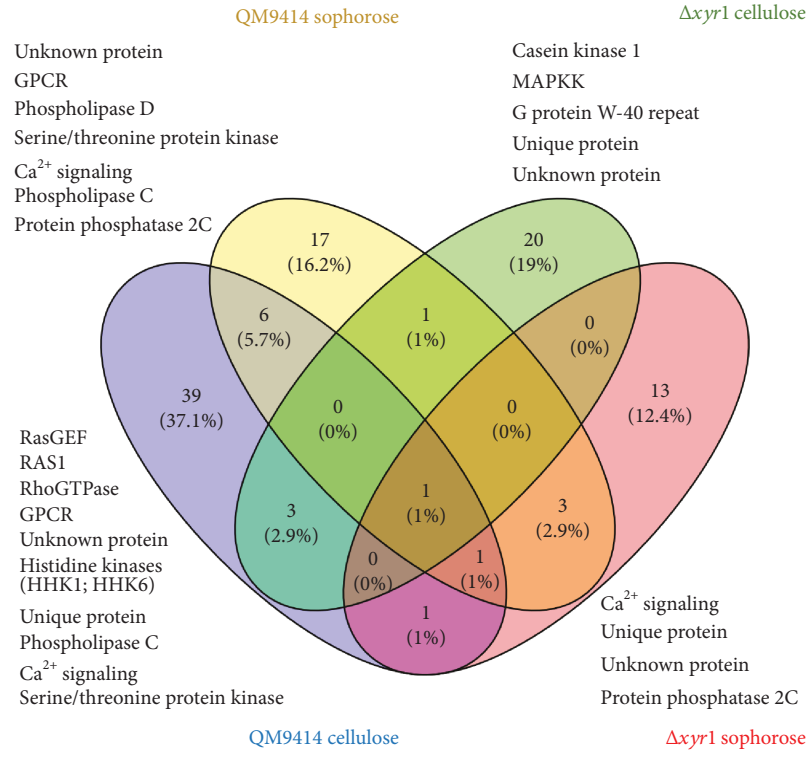

(a)

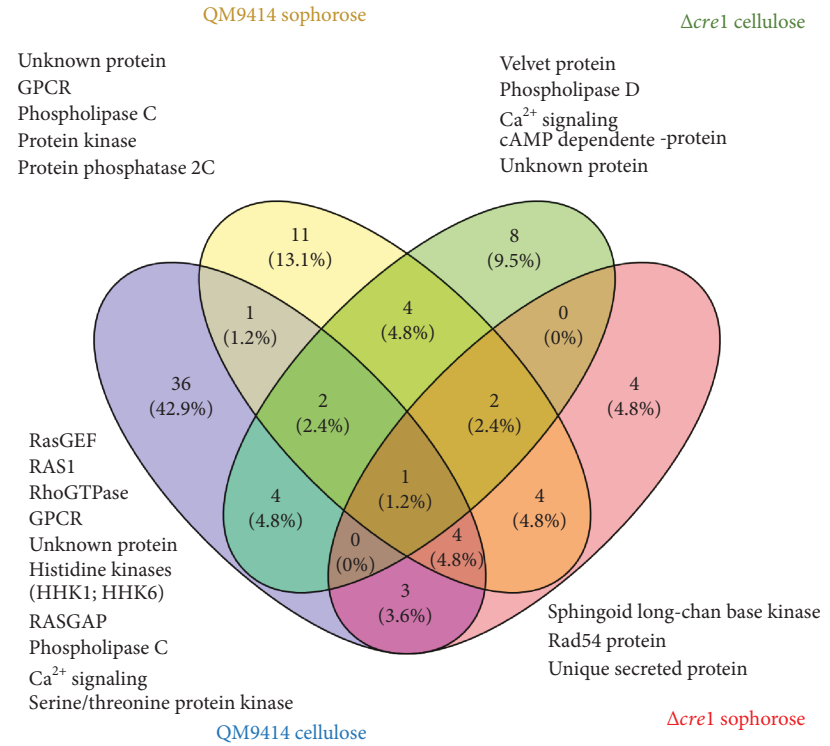

(b)

FIGURE 5: Expression pattern of differentially expressed signaling pathway genes in T. reesei during cultivation in cellulose and sophorose. (a) Comparative Venn diagram of expressed genes between the QM9414 and $\Delta x y r 1$ mutant strains in the presence of cellulose and sophorose. Venn diagram clustering was designed using Venny 2.1 tools. (b) Comparative Venn diagram of expressed genes between the QM9414 and $\Delta c r e 1$ mutant strains in the presence of cellulose and sophorose. Venn diagram clustering was designed using Venny 2.1.

downregulated genes, an unknown protein (ID 65522, 12fold) was the most repressed in the presence of cellulose. Moreover, the most repressed gene in the presence of sophorose encoded the conidiospore surface protein $\mathrm{cmp} 1$ (ID 72379) being 69-fold less expressed in this condition [35]. Curiously, this gene was the most upregulated one when the QM9414 mutant strain was grown in the presence of cellulose. This result suggests that this protein may have an important role in cellulose recognition although the aspects about the regulatory mechanisms involved with the signal transduction remain unclear.

Here, we compared the expression patterns of signaling pathway-encoding genes in two functional mutant strains of the XYR1 positive and CRE1 negative regulators of cellulase expression in $T$. reesei. The reported studies have shown there is a specific pattern of signaling pathways for the recognition of different carbon sources (Figure 5). In the QM9414 parental strain, the RAS-GTPAses (RAS-EGF, RAS1, and RhoGTPase) and histidine kinases (HHK1 and HHK6) are the main activated proteins (Figure 5(a)). Moreover, rasl gene (ID 67275) and hhk6 gene (ID 62751) were 8 -fold and 2-fold more expressed in the presence of cellulose, respectively [35]. Zhang et al. [97] showed that ras 1 plays important roles in some cellular processes such as polarized apical growth, hyphal branch formation, sporulation, and cAMP level adjustment. Additionally, the deletion of GTPase ras 2 modulates the expression of major cellulase genes and transcription factors in cellulose. The growth and protein secretion of $T$. reesei in cellulose cultures were decreased in $\Delta r h o 3$ GTPase mutant strain, suggesting rho3 is involved with secretion processes in this fungus [100].
In the presence of sophorose, we observe distinct expression patterns, being GPCR, phospholipases D and C, and $\mathrm{Ca}^{2+}$ - signaling the main pathways involved with carbon source recognition (Figure 5(a)). The $\Delta x y r 1$ mutant strain demonstrated a distinct pattern of regulation, and, in the presence of cellulose, we observed the activation of casein kinase 1 and MAPKK signaling pathways (Figure 5(a)). The gene encoding to casein kinase 1 (ID 55049) was 2.5-fold more expressed in this condition, and the MAPKK (ID 57513) was increased about 2 -fold in cellulose as the carbon source [35]. Wang et al. [113] showed that the casein kinase pathway governs chitinase expression, and beyond that, casein kinase-dependent phosphorylation has been suggested to be an important mechanism of regulation of DNA-binding zinc finger proteins, such as CRE1 [122]. These results suggest that XYR1 is a negative regulator of some genes encoding components of intracellular signaling pathways, such as MAPK and casein kinase cascades, involved with cellulose recognition being this regulation an additional mechanism of transcriptional regulation of cellulase expression.

The functional $\Delta c r e 1$ mutant strain exhibited a specific expression pattern related to signaling pathways. In the presence of cellulose, the main signaling pathways involved with cellulose sensing were $\mathrm{Ca}^{2+}$, phospholipase, cAMP, and velvet-dependent signaling pathways (Figure 5(b)). The $\mathrm{Ca}^{2+}$-dependent protein kinase (ID 62181, 5.7-fold) was the most upregulated gene in this condition. Moreover, a cAMP-dependent protein (ID 119614) was 2-fold more expressed in $\Delta c r e 1$ grown in cellulose [45]. The phospholipase D gene (ID 22331) was 3.8-fold more expressed in $\Delta c r e 1$ in the presence of cellulose [45]. Finally, the deletion of cre1 promoted a decrease of 2.3-fold in the expression 


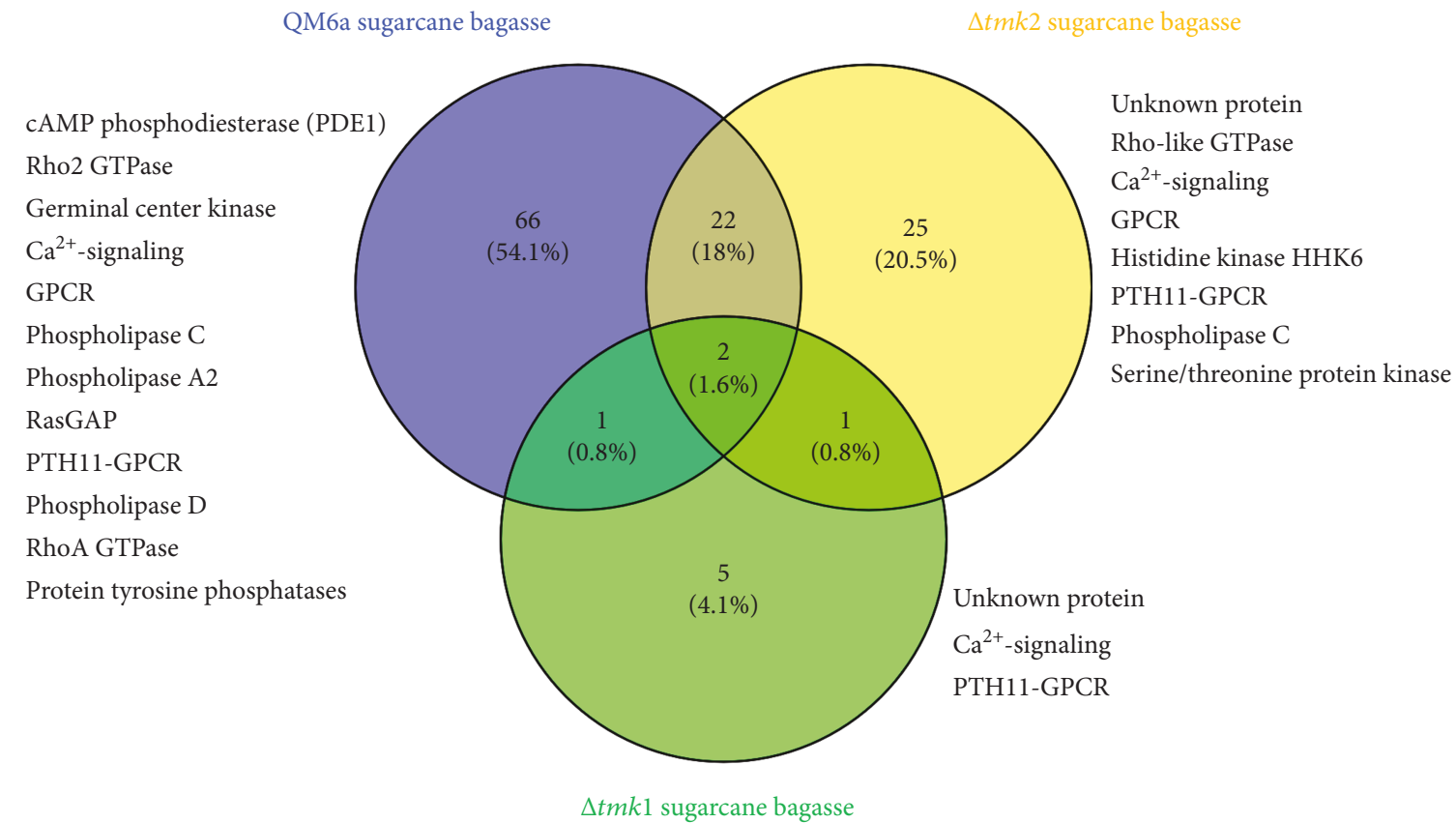

FIGURE 6: Expression pattern of differentially expressed signaling pathway genes in QM6a parental and two functional MAPK-mutant genes in the presence of sugarcane bagasse. (a) Comparative Venn diagram of expressed genes between the QM6a, $\Delta t m k 1$, and $\Delta t m k 2$ mutant strains in the presence of sugarcane bagasse. Venn diagram clustering was designed using Venny 2.1.

of regulatory protein velvet 1 (ID 122284). KarimiAghcheh et al. [84] showed the deletion of vel1 completely blocked the expression of xylanases, cellulases, and the regulator XYR1 in the presence of lactose. Since vell was downregulated with cre1 deletion, this result suggests that CRE1 might indirectly regulate the XYR1 expression in a vel1-dependent mechanism, and this may be an unclear mechanism of CCR regulation in T. reesei.

The growth of $T$. reesei QM6a in sugarcane bagasse demonstrated a specific expression profile of signalingencoding genes. In this condition, the expression of genes belonging to cAMP, GTPase, germinal center kinase, calcium, phospholipases, GPCR, protein phosphatases, and PTH11 signaling pathways was observed (Figure 6). Among these, PTH11-encoding genes were an overrepresented category, where eight genes were differentially expressed in this condition. The most upregulated PTH11 (ID 69500) was 14.5-fold more expressed in the presence of sugarcane bagasse [43]. In the filamentous fungus Neurospora crassa, PTH11 GPCR seems to be a yet-unclear key role in cellulose recognition and in the control of holocellulytic enzyme expression [123]. De Paula [43] showed in a global transcriptional analysis of two functional mutants for the MAPK signaling pathway that there is a cross talk among different signaling pathways in the presence of sugarcane bagasse. In the $\Delta t m k 2$ mutant strain, the main signaling pathways involved with the sugarcane recognition are Rho GTPase, GPCR, histidine kinase, and PTH11 GPCR (Figure 6). Interestingly, PTH11-encoding genes were also overrepresented in the tmk 2 deletion when compared to the parental strain [43]. The deletion of $t m k 1$ alters the expression of few genes belonging to signaling pathways. Only $4.1 \%$ of all genes related with intracellular signaling were involved with sugarcane bagasse recognition in $\Delta t m k 1$ mutant strain. Curiously, Vercoe et al. [124] demonstrated in Ruminococcus flavefaciens, a cellulolytic bacterium, that the phosphorylation and dephosphorylation dynamics are important for carbon source recognition and regulation of carbon metabolism. Together, our results suggest that in T. reesei, there may be a mechanism for carbon source recognition involving PTH11 GPCR, and that this process might be regulated by posttranslational events.

The understanding of how signal transduction pathways modulate cellulase gene expression has acquired attention, such as tools for strain improvement in T. reesei [125]. The adequate environmental perception is a crucial step for regulation of gene expression. Thereby, changing transmission of signals aiming at the adjustment of enzyme secretion in response to environmental conditions is an advantageous alternative to enhance the activity efficiency of genes of interest [18]. Different approaches can be employed to improve the production of enzymes by T. reesei. One of them is the manipulation of the expression of holocellulolytic-encoding genes by increasing gene expression of activators and/or decreasing expression of repressors that control the expression of the cellulose- and hemicellulose-degrading enzymes. Thus, to carry out this task, a deeper knowledge of holocellulase regulation is crucial $[23,35,45,76,126-128]$.

In order to accomplish improvement in cellulase expression, different signal transduction mechanisms can be exploited. The holocellulytic gene expression may be regulated by different factors such as light, carbon and nitrogen sources, $\mathrm{pH}$, temperature, inorganic compounds, 
transcription factors, and epigenetic events $[21,35,44,45,81$, $87,126,129-133]$. These factors and their effects in regulating intracellular signaling pathways have been well studied in Trichoderma. As an example, in T. reesei, light and photoreceptors BLR1 and BLR2, which belong to light signaling, are known to regulate expression of cellulase genes [134, 135]. Regarding $c b h 1$ and $c b h 2$, the two main cellobiohydrolases, it has been demonstrated that growth of $T$. reesei in the presence of light promotes an increase of 2 -fold in gene expression in the presence of cellulose $[134,135]$. The signal integration of light and nutrient signaling was an important discovery in the understanding of cellulase gene expression $[105,106]$. The G-protein alpha subunits GNA1 and GNA3 were described to be involved in light-dependent regulation of cellulase gene expression. Additionally, transcriptional analysis of the effect of deletion of GNB1 and GNG1 as well as the phosducin-like protein PHLP1 showed that glycosyl hydrolases are the major targets of light-dependent signaling by heterotrimeric G-proteins [109]. The intracellular level of cAMP directly affects cellulase expression [110, 136]. Nogueira et al. [111] showed that intracellular levels of cAMP were 4-fold in the presence of sophorose, and cAMP may regulate secretion of cellulolytic enzymes in $T$. reese $i$ in the presence of this sugar. Interestingly, de Paula [43] showed that deletion of MAPK gene $t m k 1$ promoted the downregulation of the main holocellulolytic genes of $T$. reesei. These results suggest that TMK1 is a positive regulator of cellulase gene expression and point this gene as a potential target for improvement engineering approaches to enhance cellulase expression in this fungus. Finally, all the knowledge about intracellular signaling pathways and its effects in the cellulase expression in $T$. reesei will provide important insights for metabolic engineering for strain improvement to be used in biotechnological industries.

\section{The New Players Potentially Involved in $T$. reesei Lignocellulosic Biomass Degradation}

In order to survive in different environments, filamentous fungi must be able to sense the surroundings and respond to it accordingly. Once the fungus senses the carbon source (whether it is sugarcane bagasse, cellulose, or sophorosecellulase inducers), a signaling cascade is activated, and it ends with increasing/decreasing the transcription level of certain genes involved in the degradation of each carbon source. However, all this sensing and responding processes are still not completely characterized. Attempts to solve this puzzle have been made by analyzing transcriptome results, and several studies have shown that $T$. reesei presents genes that code for proteins of unknown function [137].

A differential analysis of expressed genes when T. reesei was cultivated in cellulose versus glucose, in sophorose versus cellulose, and in sophorose versus glucose revealed that about 35 to $46 \%$ of the genes presented unknown function [21]. Also, when analyzing the top 10 upregulated genes in cellulose, five of them corresponded to protein of unknown function [21]. Among the top 10 upregulated genes in sophorose, there were three of unknown function. These results suggested these genes (were upregulated in inducing conditions) play an important and so far a neglected role in biomass degradation.

Some transporters have been reported to be involved with sensing external carbon sources and thus with the induction of CAZymes [48, 61]. Although the importance of these proteins has been known, specially sugar transporters, for the cellular response to the environment, there are putative transporters that have been differentially expressed [21, 35, 44, 45] and have not yet been characterized. Figure 7(a) summarizes a few genes that have been expressed in very different levels depending upon the carbon source. Among them, four copper transporters (ID 52315, ID 62716, ID 71029, and ID 108749) had transcriptional levels decreased in the presence of sophorose [21]. Supporting this result, Bak showed in 2015 that a copper transporter was downregulated in Phanerochaete chrysosporium cultivated in rice straw compared to no carbon source [138]. In 2016, dos Santos Castro showed that the deletion of $x y r 1$ caused the transcriptional levels of these genes to be upregulated in the knockout strain compared to the wild type in sophorose [35]. Deletion of the major transcription factor involved in CCR, cre1, did not result in changes in these four genes $[44,45]$. Therefore, these copper transporters may be involved in biomass degradation since copper is a cofactor required for LPMO activity [139], and the results obtained so far suggest they are regulated (directly or indirectly) by XYR1 but not by CRE1.

Another class of proteins related to biomass degradation regulation and that is still poorly characterized is transcription factor (TF). A lot of effort have been put into discovering new TF that would be important for the regulation of expression of genes that is important for an efficient biomass degradation [73, 80, 82, 140]. Antoniêto et al. [44, 45] and dos Santos Castro et al. [21, 35] studied differential expression in T. reesei cultivated in different carbon sources. Also, they have studied two transcription factors, CRE1 and XYR1, and how they affect the transcriptional level of genes related to biomass degradation. Among the transcription factors that showed differences in expression, a few unknown TF presented particularly high differences of expression Figure 7(b). The high expression of these TFs in sugarcane bagasse, cellulose, and sophorose suggests that they can play a role on the regulation of biomass degradation and should be considered targets for further studies [137]. Particularly, gene 107641, classified as a transcription factor by KOG, was repressed in sugarcane bagasse and induced in sophorose. Also, the deletion of xyr1 caused this gene (ID 107641) to be highly expressed when $T$. reesei was cultivated in sophorose, a cellulase inductor. Moreover, this TF (ID 107641) was also highly expressed in the knockout of cre 1 when cultivated in cellulose Figure $7(\mathrm{~b})$. All these results combined suggest that this TF (ID 107641) is involved in the regulation of transcription of enzymes related to biomass degradation and that XYR1 and CRE1 supposedly act as repressors for the expression of this TF. Several studies have identified genes encoding putative fungal C6 zinc fingertype transcription factors enriched among the differential 


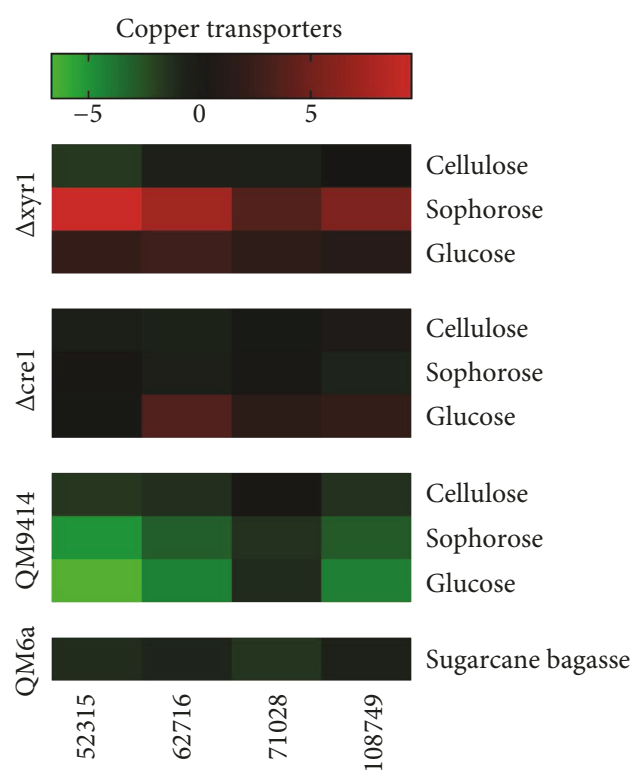

(a)

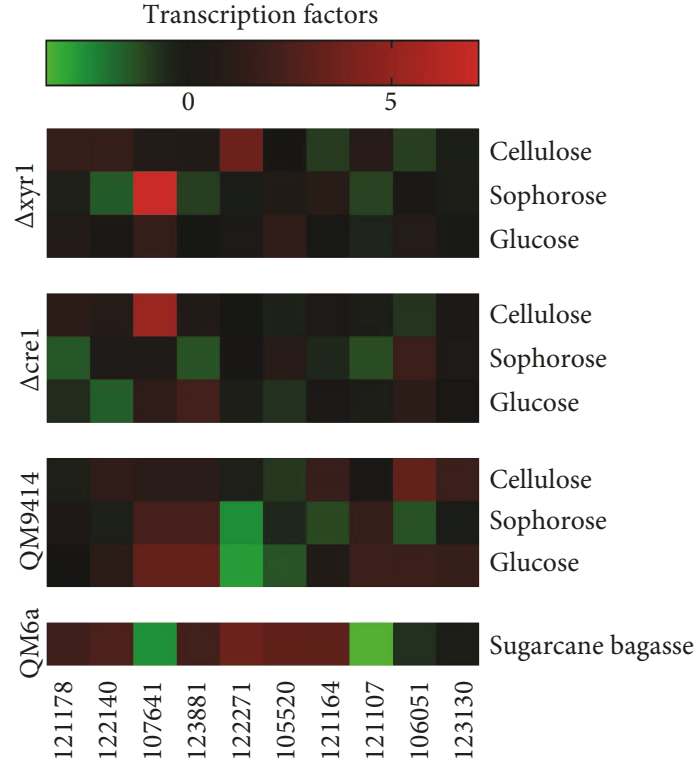

(b)

FiguRe 7: Heatmap expression of new players potentially involved with T. reesei biomass degradation. (a) Expression profile of copper transporter-encoding gene differentially expressed in T. reesei strains grown in cellulose, sophorose, glucose, and sugarcane bagasse. (b) Expression profile of transcription factor-encoding gene differentially expressed in T. reesei strains grown in cellulose, sophorose, glucose, and sugarcane bagasse. The results of gene expressions were transformed in Log2FoldChange values and employed to heat map construction using the GraphPad Prism version 7 program (https://www.graphpad.com/).

analysis [80, 141-143]. However, characterizing them according to the binding site and which gene expression it regulates is still necessary in order to have a greater knowledge of biomass degradation regulation. Therefore, the identification of novel transcription factors which transcription levels are affected by different carbon sources may be the first step for understanding more deeply how the regulation of transcription occurs. Therefore, these new findings could be used for engineering $T$. reese $i$ in order to have a new hyperproducer strain for the industry to use in biomass degradation with higher efficiency.

\section{Conclusions}

The adoption of the filamentous fungus $T$. reese $i$ as the most important holocellulase producer in biotechnology industries has been stabilized over the years. However, some aspects about holocellulase expression remain unclear. Thus, global transcriptional analyses are an excellent approach to understanding gene expression and promoting the selection of candidate genes for construction of strains producing high levels of holocellulases for plant cell wall degradation. This way, knowledge about the mechanisms involved in the recognition of environmental signals, sugar transport, and transcriptional regulatory events involved with fungal adaptation for different conditions consists in an extremely important step in the fungal biology comprehension. The integration of all these data might contribute to a better understanding of the regulatory mechanisms during lignocellulosic biomass degradation by $T$. reesei facilitating its application in fungal biotechnology.

\section{Conflicts of Interest}

The authors declare that there is no conflict of interest regarding the publication of this paper.

\section{Authors' Contributions}

Renato Graciano de Paula and Amanda Cristina Campos Antoniêto contributed equally to this work.

\section{Acknowledgments}

This work was supported by The State of São Paulo Research Foundation (FAPESP) (Processes 2016/20358-5, 2016/23233-9, and 2017/04206-3).

\section{References}

[1] G. J. Samuels, "Trichoderma: a review of biology and systematics of the genus," Mycological Research, vol. 100, no. 8, pp. 923-935, 1996.

[2] V. K. Gupta, A. S. Steindorff, R. G. de Paula et al., "The post-genomic era of Trichoderma reesei: what's next?" Trends in Biotechnology, vol. 34, no. 12, pp. 970-982, 2016.

[3] G. E. Harman, A. H. Herrera-Estrella, B. A. Horwitz, and M. Lorito, "Special issue: Trichoderma-from basic biology to biotechnology," Microbiology, vol. 158, no. 1, pp. 1-2, 2012.

[4] A. Schuster and M. Schmoll, "Biology and biotechnology of Trichoderma," Applied Microbiology and Biotechnology, vol. 87, no. 3, pp. 787-799, 2010. 
[5] C. P. Kubicek, M. Komon-Zelazowska, and I. S. Druzhinina, "Fungal genus Hypocrea/Trichoderma: from barcodes to biodiversity," Journal of Zhejiang University Science B, vol. 9, no. 10, pp. 753-763, 2008.

[6] D. Tisch and M. Schmoll, "Targets of light signalling in Trichoderma reesei," BMC Genomics, vol. 14, no. 1, p. 657, 2013.

[7] A. Schuster, C. P. Kubicek, M. A. Friedl, I. S. Druzhinina, and M. Schmoll, "Impact of light on Hypocrea jecorina and the multiple cellular roles of ENVOY in this process," $B M C$ Genomics, vol. 8, no. 1, p. 449, 2007.

[8] I. Druzhinina and C. P. Kubicek, "Species concepts and biodiversity in Trichoderma and Hypocrea: from aggregate species to species clusters?," Journal of Zhejiang University Science B, vol. 6, no. 2, pp. 100-112, 2005.

[9] G. E. Harman, "Overview of mechanisms and uses of Trichoderma spp," Phytopathology, vol. 96, no. 2, pp. 190-194, 2006.

[10] Y. Galante, A. De Conti, and R. Monteverdi, Application of Trichoderma Enzymes in the Food and Feed Industries, G. E. Harman and C. P. Kubicek, Eds., Taylor and Francis, London, 1998.

[11] Y. Galante, A. De Conti, and R. Monteverdi, Application of Trichoderma Enzymes in the Textile Industry, G. E. Harman and C. P. Kubicek, Eds., Taylor and Francis, London, 1998.

[12] J. Buchert, T. Oksanen, J. Pere, M. Siika-Aho, A. Suurnäkki, and L. Viikari, Applications of Trichoderma reesei Enzymes in the Pulp and Paper Industry, G. E. Harman and C. P. Kubicek, Eds., Taylor and Francis, London, 1998.

[13] S. Pereira, L. Maehara, C. Machado, and C. Farinas, "2G ethanol from the whole sugarcane lignocellulosic biomass," Biotechnology for Biofuels, vol. 8, no. 1, p. 44, 2015.

[14] R. H. Bischof, J. Ramoni, and B. Seiboth, "Cellulases and beyond: the first 70 years of the enzyme producer Trichoderma reesei," Microbial Cell Factories, vol. 15, no. 1, p. 106, 2016.

[15] Y. Li, C. Liu, F. Bai, and X. Zhao, "Overproduction of cellulase by Trichoderma reesei RUT C30 through batch-feeding of synthesized low-cost sugar mixture," Bioresource Technology, vol. 216, pp. 503-510, 2016.

[16] J. Huang, D. Chen, Y. Wei et al., "Direct ethanol production from lignocellulosic sugars and sugarcane bagasse by a recombinant Trichoderma reesei strain HJ48," The Scientific World Journal, vol. 2014, Article ID 798683, 8 pages, 2014.

[17] S. S. Adav and S. K. Sze, "Trichoderma secretome: an overview," in Biotechnology and Biology of Trichoderma, V. K. Gupta, M. Schmoll, A. Herrera-Estrella, R. S. Upadhyay, I. Druzhinina, and M. G. Tuohy, Eds., pp. 103-114, Elsevier, Waltham, 1st edition, 2014.

[18] H. Bazafkan, D. Tisch, and M. Schmoll, "Regulation of glycoside hydrolase expression in Trichoderma," in Biotechnology and Biology of Trichoderma, V. K. Gupta, M. Schmoll, A. Herrera-Estrella, R. Upadhyay, I. Druzhinina, and M. G. Tuohy, Eds., p. 527, Elsevier, 2014.

[19] J. Gao, Y. Qian, Y. Wang, Y. Qu, and Y. Zhong, "Production of the versatile cellulase for cellulose bioconversion and cellulase inducer synthesis by genetic improvement of Trichoderma reesei," Biotechnology for Biofuels, vol. 10, no. 1, p. 272, 2017.

[20] Q. Zhou, J. Xu, Y. Kou et al., "Differential involvement of $\beta$-glucosidases from Hypocrea jecorina in rapid induction of cellulase genes by cellulose and cellobiose," Eukaryotic Cell, vol. 11, no. 11, pp. 1371-1381, 2012.
[21] L. dos Santos Castro, W. Pedersoli, A. C. Antoniêto et al., "Comparative metabolism of cellulose, sophorose and glucose in Trichoderma reesei using high-throughput genomic and proteomic analyses," Biotechnology for Biofuels, vol. 7, no. 1, p. 41, 2014.

[22] C. P. Kubicek, A. Herrera-Estrella, V. Seidl-Seiboth et al., "Comparative genome sequence analysis underscores mycoparasitism as the ancestral life style of Trichoderma," Genome Biology, vol. 12, no. 4, article R40, 2011.

[23] L. dos Santos Castro, A. C. C. Antoniêto, W. R. Pedersoli, R. Silva-Rocha, G. F. Persinoti, and R. N. Silva, "Expression pattern of cellulolytic and xylanolytic genes regulated by transcriptional factors XYR1 and CRE1 are affected by carbon source in Trichoderma reesei," Gene Expression Patterns, vol. 14, no. 2, pp. 88-95, 2014.

[24] E. A. Znameroski, S. T. Coradetti, C. M. Roche et al., "Induction of lignocellulose-degrading enzymes in Neurospora crassa by cellodextrins," Proceedings of the National Academy of Sciences of the United States of America, vol. 109, no. 16, pp. 6012-6017, 2012.

[25] Z. Anwar, M. Gulfraz, and M. Irshad, "Agro-industrial lignocellulosic biomass a key to unlock the future bio-energy: a brief review," Journal of Radiation Research and Applied Sciences, vol. 7, no. 2, pp. 163-173, 2014.

[26] V. Vandenbossche, J. Brault, G. Vilarem et al., "A new lignocellulosic biomass deconstruction process combining thermo-mechano chemical action and bio-catalytic enzymatic hydrolysis in a twin-screw extruder," Industrial Crops and Products, vol. 55, pp. 258-266, 2014.

[27] J. K. Saini, R. Saini, and L. Tewari, "Lignocellulosic agriculture wastes as biomass feedstocks for second-generation bioethanol production: concepts and recent developments," 3 Biotech, vol. 5, no. 4, pp. 337-353, 2015.

[28] C. A. Cardona, J. A. Quintero, and I. C. Paz, "Production of bioethanol from sugarcane bagasse: status and perspectives," Bioresource Technology, vol. 101, no. 13, pp. 4754-4766, 2010.

[29] A. V. Gusakov, "Alternatives to Trichoderma reesei in biofuel production," Trends in Biotechnology, vol. 29, no. 9, pp. 419-425, 2011.

[30] L. R. Lynd, W. H. van Zyl, J. E. Mcbride, and M. Laser, "Consolidated bioprocessing of cellulosic biomass: an update," Current Opinion in Biotechnology, vol. 16, no. 5, pp. 577-583, 2005.

[31] L. R. Lynd, P. J. Weimer, W. H. van Zyl, and I. S. Pretorius, "Microbial cellulose utilization: fundamentals and biotechnology," Microbiology and Molecular Biology Reviews, vol. 66, no. 3, pp. 506-577, 2002.

[32] Y. Shida, T. Furukawa, and W. Ogasawara, "Deciphering the molecular mechanisms behind cellulase production in Trichoderma reesei, the hyper-cellulolytic filamentous fungus," Bioscience, Biotechnology, and Biochemistry, vol. 80, no. 9, pp. 1712-1729, 2016.

[33] D. Martinez, R. M. Berka, B. Henrissat et al., "Genome sequencing and analysis of the biomass-degrading fungus Trichoderma reesei (syn. Hypocrea jecorina)," Nature Biotechnology, vol. 26, no. 5, pp. 553-560, 2008.

[34] M. Schmoll, C. Dattenböck, N. Carreras-Villaseñor et al., "The genomes of three uneven siblings: footprints of the lifestyles of three Trichoderma species," Microbiology and Molecular Biology Reviews, vol. 80, no. 1, pp. 205-327, 2016. 
[35] L. dos Santos Castro, R. G. de Paula, A. C. C. Antoniêto, G. F. Persinoti, R. Silva-Rocha, and R. N. Silva, "Understanding the role of the master regulator XYR1 in Trichoderma reesei by global transcriptional analysis," Frontiers in Microbiology, vol. 7, p. 175, 2016.

[36] R. J. Quinlan, M. D. Sweeney, L. Lo Leggio et al., "Insights into the oxidative degradation of cellulose by a copper metalloenzyme that exploits biomass components," Proceedings of the National Academy of Sciences of the United States of America, vol. 108, no. 37, pp. 15079-15084, 2011.

[37] M. Saloheimo, M. Paloheimo, S. Hakola et al., "Swollenin, a Trichoderma reesei protein with sequence similarity to the plant expansins, exhibits disruption activity on cellulosic materials," European Journal of Biochemistry, vol. 269, no. 17, pp. 4202-4211, 2002.

[38] M. Häkkinen, M. Arvas, M. Oja et al., "Re-annotation of the CAZy genes of Trichoderma reesei and transcription in the presence of lignocellulosic substrates," Microbial Cell Factories, vol. 11, no. 1, p. 134, 2012.

[39] I. S. Druzhinina and C. P. Kubicek, "Genetic engineering of Trichoderma reesei cellulases and their production," Microbial Biotechnology, vol. 10, no. 6, pp. 1485-1499, 2017.

[40] S. K. Brady, S. Sreelatha, Y. Feng, S. P. S. Chundawat, and M. J. Lang, "Cellobiohydrolase 1 from Trichoderma reesei degrades cellulose in single cellobiose steps," Nature Communications, vol. 6, no. 1, p. 10149, 2015.

[41] V. K. Gupta, Biotechnology and Biology of Trichoderma, Elsevier, 2014.

[42] J. Strakowska, L. Błaszczyk, and J. Chełkowski, “The significance of cellulolytic enzymes produced by Trichoderma in opportunistic lifestyle of this fungus," Journal of Basic Microbiology, vol. 54, no. S1, pp. S2-S13, 2014.

[43] R. G. De Paula, Characterization of the MAPK-dependent signaling pathway in the regulation of cellulase expression by the fungus Trichoderma reesei (Hypocrea jecorina), University of Sao Paulo, 2017.

[44] A. C. Campos Antoniêto, R. Graciano de Paula, L. d. Santos Castro, R. Silva-Rocha, G. Felix Persinoti, and R. Nascimento Silva, "Trichoderma reesei CRE1-mediated carbon catabolite repression in response to sophorose through RNA sequencing analysis," Current Genomics, vol. 17, no. 2, pp. 119-131, 2016.

[45] A. C. C. Antoniêto, L. dos Santos Castro, R. Silva-Rocha, G. F. Persinoti, and R. N. Silva, "Defining the genome-wide role of CRE1 during carbon catabolite repression in Trichoderma reesei using RNA-Seq analysis," Fungal Genetics and Biology, vol. 73, pp. 93-103, 2014.

[46] C. P. Kubicek, R. Messner, F. Gruber, M. Mandels, and E. M. Kubicek-Pranz, "Triggering of cellulase biosynthesis by cellulose in Trichoderma reesei: involvement of a constitutive, sophorose-inducible, glucose-inhibited $\beta$-diglucoside permease," Journal of Biological Chemistry, vol. 268, no. 26, pp. 19364-19368, 1993.

[47] C. P. Kubicek, R. Messner, F. Gruber, R. L. Mach, and E. M. Kubicek-Pranz, "The Trichoderma cellulase regulatory puzzle: from the interior life of a secretory fungus," Enzyme and Microbial Technology, vol. 15, no. 2, pp. 90-99, 1993.

[48] W. Zhang, Y. Kou, J. Xu et al., "Two major facilitator superfamily sugar transporters from Trichoderma reesei and their roles in induction of cellulase biosynthesis," Journal of Biological Chemistry, vol. 288, no. 46, pp. 32861-32872, 2013.
[49] E. M. Quistgaard, C. Löw, F. Guettou, and P. Nordlund, "Understanding transport by the major facilitator superfamily (MFS): structures pave the way," Nature Reviews Molecular Cell Biology, vol. 17, no. 2, pp. 123-132, 2016.

[50] S. S. Pao, I. T. Paulsen, and M. H. Saier Jr., "Major facilitator superfamily," Microbiology and Molecular Biology Reviews, vol. 62, no. 1, pp. 1-34, 1998.

[51] P. Cai, R. Gu, B. Wang et al., "Evidence of a critical role for cellodextrin transporte 2 (CDT-2) in both cellulose and hemicellulose degradation and utilization in Neurospora crassa," PLoS One, vol. 9, no. 2, article e89330, 2014.

[52] J. d. O. Porciuncula, T. Furukawa, Y. Shida et al., "Identification of major facilitator transporters involved in cellulase production during lactose culture of Trichoderma reesei PC-3-7," Bioscience, Biotechnology, and Biochemistry, vol. 77, no. 5, pp. 1014-1022, 2014.

[53] C. Ivanova, J. A. Bååth, B. Seiboth, and C. P. Kubicek, "Systems analysis of lactose metabolism in Trichoderma reesei identifies a lactose permease that is essential for cellulase induction," PLoS One, vol. 8, no. 5, article e62631, 2013.

[54] N. Chaudhary, I. Kumari, P. Sandhu, M. Ahmed, and Y. Akhter, "Proteome scale census of major facilitator superfamily transporters in Trichoderma reesei using protein sequence and structure based classification enhanced ranking," Gene, vol. 585, no. 1, pp. 166-176, 2016.

[55] W. Vongsangnak, M. Salazar, K. Hansen, and J. Nielsen, "Genome-wide analysis of maltose utilization and regulation in aspergilli," Microbiology, vol. 155, no. 12, pp. 3893-3902, 2009.

[56] J. E. Galagan, S. E. Calvo, K. A. Borkovich et al., "The genome sequence of the filamentous fungus Neurospora crassa," Nature, vol. 422, no. 6934, pp. 859-868, 2003.

[57] C. J. Law, P. C. Maloney, and D.-N. Wang, "Ins and outs of major facilitator superfamily antiporters," Annual Review of Microbiology, vol. 62, no. 1, pp. 289-305, 2008.

[58] N. Yan, "Structural advances for the major facilitator superfamily (MFS) transporters," Trends in Biochemical Sciences, vol. 38, no. 3, pp. 151-159, 2013.

[59] A. C. Colabardini, L. N. Ries, N. Brown et al., "Functional characterization of a xylose transporter in Aspergillus nidulans," Biotechnology for Biofuels, vol. 7, no. 1, p. 46, 2014.

[60] W. Zhang, Y. Cao, J. Gong, X. Bao, G. Chen, and W. Liu, "Identification of residues important for substrate uptake in a glucose transporter from the filamentous fungus Trichoderma reesei," Scientific Reports, vol. 5, no. 1, article 13829, 2015.

[61] Z. B. Huang, X. Z. Chen, L. N. Qin, H. Q. Wu, X. Y. Su, and Z. Y. Dong, "A novel major facilitator transporter TrSTR1 is essential for pentose utilization and involved in xylanase induction in Trichoderma reesei," Biochemical and Biophysical Research Communications, vol. 460, no. 3, pp. 663-669, 2015.

[62] L. Ries, S. T. Pullan, S. Delmas, S. Malla, M. J. Blythe, and D. B. Archer, "Genome-wide transcriptional response of Trichoderma reesei to lignocellulose using RNA sequencing and comparison with Aspergillus niger," BMC Genomics, vol. 14, no. 1, p. 541, 2013.

[63] L. Atanasova, S. L. Crom, S. Gruber et al., "Comparative transcriptomics reveals different strategies of Trichoderma mycoparasitism," BMC Genomics, vol. 14, no. 1, p. 121, 2013. 
[64] J. Kang, J.-U. Hwang, M. Lee et al., "PDR-type ABC transporter mediates cellular uptake of the phytohormone abscisic acid," Proceedings of the National Academy of Sciences of the United States of America, vol. 107, no. 5, pp. 2355-2360, 2010.

[65] R. Bischof, L. Fourtis, A. Limbeck, C. Gamauf, B. Seiboth, and C. P. Kubicek, "Comparative analysis of the Trichoderma reesei transcriptome during growth on the cellulase inducing substrates wheat straw and lactose," Biotechnology for Biofuels, vol. 6, no. 1, p. 127, 2013.

[66] E. Lamping, P. V. Baret, A. R. Holmes, B. C. Monk, A. Goffeau, and R. D. Cannon, "Fungal PDR transporters: phylogeny, topology, motifs and function," Fungal Genetics and Biology, vol. 47, no. 2, pp. 127-142, 2010.

[67] M. Ruocco, S. Lanzuise, F. Vinale et al., "Identification of a new biocontrol gene in Trichoderma atroviride: the role of an $\mathrm{ABC}$ transporter membrane pump in the interaction with different plant-pathogenic fungi," Molecular Plant-Microbe Interactions, vol. 22, no. 3, pp. 291-301, 2009.

[68] M. Karlsson, M. B. Durling, J. Choi et al., "Insights on the evolution of mycoparasitism from the genome of Clonostachys rosea," Genome Biology and Evolution, vol. 7, no. 2, pp. 465-480, 2015.

[69] S. Wilkens, "Structure and mechanism of ABC transporters," F1000Prime Reports, vol. 7, p. 14, 2015.

[70] M. G. L. Elferink, S. V. Albers, W. N. Konings, and A. J. M. Driessen, "Sugar transport in Sulfolobus solfataricus is mediated by two families of binding protein-dependent ABC transporters," Molecular Microbiology, vol. 39, no. 6, pp. 1494-1503, 2001.

[71] A. Watanabe, K. Hiraga, M. Suda, H. Yukawa, and M. Inui, "Functional characterization of Corynebacterium alkanolyticum $\beta$-xylosidase and xyloside ABC transporter in Corynebacterium glutamicum," Applied and Environmental Microbiology, vol. 81, no. 12, pp. 4173-4183, 2015.

[72] S. M. Koning, M. G. L. Elferink, W. N. Konings, and A. J. M. Driessen, "Cellobiose uptake in the hyperthermophilic archaeon Pyrococcus furiosus is mediated by an inducible, high-affinity ABC transporter," Journal of Bacteriology, vol. 183, no. 17, pp. 4979-4984, 2001.

[73] T. Furukawa, Y. Shida, N. Kitagami et al., "Identification of specific binding sites for XYR1, a transcriptional activator of cellulolytic and xylanolytic genes in Trichoderma reesei," Fungal Genetics and Biology, vol. 46, no. 8, pp. 564-574, 2009.

[74] T. Nakari-Setala, M. Paloheimo, J. Kallio, J. Vehmaanpera, M. Penttila, and M. Saloheimo, "Genetic modification of carbon catabolite repression in Trichoderma reesei for improved protein production," Applied and Environmental Microbiology, vol. 75, no. 14, pp. 4853-4860, 2009.

[75] T. Portnoy, A. Margeot, R. Linke et al., "The CRE1 carbon catabolite repressor of the fungus Trichoderma reesei: a master regulator of carbon assimilation," BMC Genomics, vol. 12, no. 1, p. 269, 2011.

[76] T. Portnoy, A. Margeot, V. Seidl-Seiboth et al., "Differential regulation of the cellulase transcription factors XYR1, ACE2, and ACE1 in Trichoderma reesei strains producing high and low levels of cellulase," Eukaryotic Cell, vol. 10, no. 2, pp. 262-271, 2011.

[77] E. Akel, B. Metz, B. Seiboth, and C. P. Kubicek, "Molecular regulation of arabinan and L-arabinose metabolism in Hypocrea jecorina (Trichoderma reesei)," Eukaryotic Cell, vol. 8, no. 12, pp. 1837-1844, 2009.
[78] A. R. Stricker, K. Grosstessner-Hain, E. Wurleitner, and R. L. Mach, "Xyr1 (xylanase regulator 1) regulates both the hydrolytic enzyme system and D-xylose metabolism in Hypocrea jecorina," Eukaryotic Cell, vol. 5, no. 12, pp. 2128-2137, 2006.

[79] N. Aro, A. Saloheimo, M. Ilmén, and M. Penttilä, “ACEII, a novel transcriptional activator involved in regulation of cellulase and xylanase genes of Trichoderma reesei," The Journal of Biological Chemistry, vol. 276, no. 26, pp. 24309-24314, 2001.

[80] M. Häkkinen, M. J. Valkonen, A. Westerholm-Parvinen et al., "Screening of candidate regulators for cellulase and hemicellulase production in Trichoderma reesei and identification of a factor essential for cellulase production," Biotechnology for Biofuels, vol. 7, no. 1, p. 14, 2014.

[81] S. Zeilinger, M. Schmoll, M. Pail, R. L. Mach, and C. P. Kubicek, "Nucleosome transactions on the Hypocrea jecorina (Trichoderma reesei) cellulase promoter $c b h 2$ associated with cellulase induction," Molecular Genetics and Genomics, vol. 270, no. 1, pp. 46-55, 2003.

[82] M. Nitta, T. Furukawa, Y. Shida et al., "A new $\mathrm{Zn}(\mathrm{II})_{2} \mathrm{Cys}_{6}{ }^{-}$ type transcription factor BglR regulates $\beta$-glucosidase expression in Trichoderma reesei," Fungal Genetics and Biology, vol. 49, no. 5, pp. 388-397, 2012.

[83] B. Seiboth, R. A. Karimi, P. A. Phatale et al., "The putative protein methyltransferase LAE1 controls cellulase gene expression in Trichoderma reesei," Molecular Microbiology, vol. 84, no. 6, pp. 1150-1164, 2012.

[84] R. Karimi Aghcheh, Z. Németh, L. Atanasova et al., "The VELVET A orthologue VEL1 of Trichoderma reesei regulates fungal development and is essential for cellulase gene expression," PLoS One, vol. 9, no. 11, article e112799, 2014.

[85] N. Aro, M. Ilmen, A. Saloheimo, and M. Penttila, "ACEI of Trichoderma reesei is a repressor of cellulase and xylanase expression," Applied and Environmental Microbiology, vol. 69, no. 1, pp. 56-65, 2003.

[86] Y. Cao, F. Zheng, L. Wang et al., "Rce1, a novel transcriptional repressor, regulates cellulase gene expression by antagonizing the transactivator Xyr1 in Trichoderma reesei," Molecular Microbiology, vol. 105, no. 1, pp. 65-83, 2017.

[87] L. Ries, N. J. Belshaw, M. Ilmén, M. E. Penttilä, M. Alapuranen, and D. B. Archer, "The role of CRE1 in nucleosome positioning within the cbh1 promoter and coding regions of Trichoderma reesei," Applied Microbiology and Biotechnology, vol. 98, no. 2, pp. 749-762, 2014.

[88] B. Van Vu, K. T. M. Pham, and H. Nakayashiki, "Substrateinduced transcriptional activation of the MoCel7C cellulase gene is associated with methylation of histone $\mathrm{H} 3$ at lysine 4 in the rice blast fungus Magnaporthe oryzae," Applied and Environmental Microbiology, vol. 79, no. 21, pp. 6823-6832, 2013.

[89] Q. Xin, Y. Gong, X. Lv, G. Chen, and W. Liu, "Trichoderma reesei histone acetyltransferase Gcn 5 regulates fungal growth, conidiation, and cellulase gene expression," Current Microbiology, vol. 67, no. 5, pp. 580-589, 2013.

[90] H. Hirasawa, K. Shioya, T. Furukawa et al., "Engineering of the Trichoderma reesei xylanase3 promoter for efficient enzyme expression," Applied Microbiology and Biotechnology, vol. 102, no. 6, pp. 2737-2752, 2018.

[91] G. Zou, S. Shi, Y. Jiang et al., "Construction of a cellulase hyper-expression system in Trichoderma reesei by promoter and enzyme engineering," Microbial Cell Factories, vol. 11, no. 1, p. $21,2012$. 
[92] F. Uzbas, U. Sezerman, L. Hartl, C. P. Kubicek, and B. Seiboth, "A homologous production system for Trichoderma reesei secreted proteins in a cellulase-free background," Applied Microbiology and Biotechnology, vol. 93, no. 4, pp. 1601-1608, 2012.

[93] T. Liu, T. Wang, X. Li, and X. Liu, "Improved heterologous gene expression in Trichoderma reesei by cellobiohydrolase I gene (cbh1) promoter optimization," Acta Biochimica et Biophysica Sinica, vol. 40, no. 2, pp. 158-165, 2008.

[94] Y.-S. Bahn, C. Xue, A. Idnurm, J. C. Rutherford, J. Heitman, and M. E. Cardenas, "Sensing the environment: lessons from fungi," Nature Reviews Microbiology, vol. 5, no. 1, pp. 57-69, 2007.

[95] M. Schmoll, "The information highways of a biotechnological workhorse-signal transduction in Hypocrea jecorina," BMC Genomics, vol. 9, no. 1, p. 430, 2008.

[96] M. Saloheimo and T. M. Pakula, "The cargo and the transport system: secreted proteins and protein secretion in Trichoderma reesei (Hypocrea jecorina)," Microbiology, vol. 158, no. 1, pp. 46-57, 2012.

[97] J. Zhang, Y. Zhang, Y. Zhong, Y. Qu, and T. Wang, "Ras GTPases modulate morphogenesis, sporulation and cellulase gene expression in the cellulolytic fungus Trichoderma reesei," PLoS One, vol. 7, no. 11, article e48786, 2012.

[98] S. Zeilinger, B. Reithner, V. Scala, I. Peissl, M. Lorito, and R. L. Mach, "Signal transduction by Tga3, a novel G protein alpha subunit of Trichoderma atroviride," Applied and Environmental Microbiology, vol. 71, no. 3, pp. 1591-1597, 2005.

[99] C. A. D'Souza and J. Heitman, "Conserved cAMP signaling cascades regulate fungal development and virulence," FEMS Microbiology Reviews, vol. 25, no. 3, pp. 349-364, 2001.

[100] T. Vasara, M. Saloheimo, S. Keränen, and M. Penttilä, "Trichoderma reesei rho3, a homologue of yeast $\mathrm{RHO}$, suppresses the growth defect of yeast sec15-1 mutation," Current Genetics, vol. 40, no. 2, pp. 119-127, 2001.

[101] R. Morawetz, H. Mischak, J. Goodnight, T. Lendenfeld, J. F. Mushinsky, and C. P. Kubicek, "A protein kinaseencoding gene, $p k t l$, from Trichoderma reesei, homologous to the yeast YPK1 and YPK2 (YKR2) genes," Gene, vol. 146, no. 2, pp. 309-310, 1994.

[102] R. Morawetz, T. Lendenfeld, H. Mischak et al., "Cloning and characterisation of genes ( $p k c 1$ and $p k c A)$ encoding protein kinase $\mathrm{C}$ homologues from Trichoderma reesei and Aspergillus niger," Molecular and General Genetics $M G G$, vol. 250, no. 1, pp. 17-28, 1996.

[103] T. Lendenfeld and P. C. Kubicek, "Characterization and properties of protein kinase $\mathrm{C}$ from the filamentous fungus Trichoderma reesei," Biochemical Journal, vol. 330, no. 2, pp. 689-694, 1998.

[104] M. Wang, M. Zhang, L. Li et al., "Role of Trichoderma reesei mitogen-activated protein kinases (MAPKs) in cellulase formation," Biotechnology for Biofuels, vol. 10, no. 1, p. 99, 2017.

[105] C. Seibel, G. Gremel, R. do Nascimento Silva, A. Schuster, C. P. Kubicek, and M. Schmoll, "Light-dependent roles of the G-protein $\alpha$ subunit GNA1 of Hypocrea jecorina (anamorph Trichoderma reesei)," BMC Biology, vol. 7, no. 1, p. 58, 2009.

[106] M. Schmoll, A. Schuster, R. N. Silva, and C. P. Kubicek, "The G-alpha protein GNA3 of Hypocrea jecorina (Anamorph Trichoderma reesei) regulates cellulase gene expression in the presence of light," Eukaryotic Cell, vol. 8, no. 3, pp. 410420, 2009.

[107] K. Brunner, M. Omann, M. E. Pucher et al., “Trichoderma G protein-coupled receptors: functional characterisation of a cAMP receptor-like protein from Trichoderma atroviride," Current Genetics, vol. 54, no. 6, pp. 283-299, 2008.

[108] M. R. Omann, S. Lehner, C. Escobar Rodriguez, K. Brunner, and S. Zeilinger, "The seven-transmembrane receptor Gpr1 governs processes relevant for the antagonistic interaction of Trichoderma atroviride with its host," Microbiology, vol. 158, no. 1, pp. 107-118, 2012.

[109] D. Tisch, C. P. Kubicek, and M. Schmoll, "The phosducin-like protein PhLP1 impacts regulation of glycoside hydrolases and light response in Trichoderma reesei," BMC Genomics, vol. 12, no. 1, p. 613, 2011.

[110] S. Sestak and V. Farkas, "Metabolic regulation of endoglucanase synthesis in Trichoderma reesei: participation of cyclic AMP and glucose-6-phosphate," Canadian Journal of Microbiology, vol. 39, no. 3, pp. 342-347, 1993.

[111] K. M. V. Nogueira, M. d. N. Costa, R. G. de Paula, F. C. Mendonça-Natividade, R. Ricci-Azevedo, and R. N. Silva, "Evidence of cAMP involvement in cellobiohydrolase expression and secretion by Trichoderma reesei in presence of the inducer sophorose," BMC Microbiology, vol. 15, no. 1, p. 195, 2015.

[112] A. Schuster, D. Tisch, V. Seidl-Seiboth, C. P. Kubicek, and M. Schmoll, "Roles of protein kinase A and adenylate cyclase in light-modulated cellulase regulation in Trichoderma reesei," Applied and Environmental Microbiology, vol. 78, no. 7, pp. 2168-2178, 2012.

[113] M. Wang, H. Yang, M. Zhang et al., "Functional analysis of Trichoderma reesei CKII $\alpha 2$, a catalytic subunit of casein kinase II," Applied Microbiology and Biotechnology, vol. 99, no. 14, pp. 5929-5938, 2015.

[114] R. He, W. Guo, and D. Zhang, "An ethanolamine kinase Eki1 affects radial growth and cell wall integrity in Trichoderma reesei," FEMS Microbiology Letters, vol. 362, no. 17, article fnv133, 2015.

[115] M. Wang, Q. Zhao, J. Yang et al., “A mitogen-activated protein kinase Tmk3 participates in high osmolarity resistance, cell wall integrity maintenance and cellulase production regulation in Trichoderma reesei," PLoS One, vol. 8, no. 8, article e72189, 2013.

[116] M. Wang, Y. Dong, Q. Zhao et al., "Identification of the role of a MAP kinase Tmk2 in Hypocrea jecorina (Trichoderma reesei)," Scientific Reports, vol. 4, no. 1, article 6732, 2015.

[117] F. Chen, X. Z. Chen, X. Y. Su et al., "An Ime2-like mitogenactivated protein kinase is involved in cellulase expression in the filamentous fungus Trichoderma reesei," Biotechnology Letters, vol. 37, no. 10, pp. 2055-2062, 2015.

[118] D. E. Clapham, "Calcium signaling," Cell, vol. 131, no. 6, pp. 1047-1058, 2007.

[119] L. Navazio, B. Baldan, R. Moscatiello et al., "Calciummediated perception and defense responses activated in plant cells by metabolite mixtures secreted by the biocontrol fungus Trichoderma atroviride," BMC Plant Biology, vol. 7, no. 1, p. 41, 2007.

[120] R. L. Mach, S. Zeilinger, D. Kristufek, and C. P. Kubicek, " $\mathrm{Ca}^{2+}$-calmodulin antagonists interfere with xylanase formation and secretion in Trichoderma reesei," Biochimica et 
Biophysica Acta (BBA) - Molecular Cell Research, vol. 1403, no. 3, pp. 281-289, 1998.

[121] D. Tisch, C. P. Kubicek, and M. Schmoll, "New insights into the mechanism of light modulated signaling by heterotrimeric G-proteins: ENVOY acts on gnal and gna3 and adjusts cAMP levels in Trichoderma reesei (Hypocrea jecorina)," Fungal Genetics and Biology, vol. 48, no. 6, pp. 631-640, 2011.

[122] A. Cziferszky, R. L. Mach, and C. P. Kubicek, "Phosphorylation positively regulates DNA binding of the carbon catabolite repressor Cre1 of Hypocrea jecorina (Trichoderma reesei)," The Journal of Biological Chemistry, vol. 277, no. 17, pp. 14688-14694, 2002.

[123] I. E. Cabrera, I. V. Pacentine, A. Lim et al., "Global analysis of predicted $G$ protein-coupled receptor genes in the filamentous fungus, Neurospora crassa," G3: Genes, Genomes, Genetics, vol. 5, no. 12, pp. 27292743, 2015.

[124] P. E. Vercoe, S. A. Kocherginskaya, and B. A. White, "Differential protein phosphorylation-dephosphorylation in response to carbon source in Ruminococcus flavefaciens FD-1," Journal of Applied Microbiology, vol. 94, no. 6, pp. 974-980, 2003.

[125] D. Tisch and M. Schmoll, "Novel approaches to improve cellulase biosynthesis for biofuel production-adjusting signal transduction pathways in the biotechnological workhorse Trichoderma reesei," in Biofuel Production--Recent Developments and Prospects, M. A. Santos Bernardes, Ed., pp. 199-224, Intech, Rijeka, Croatia, 2011.

[126] T. M. Mello-de-Sousa, A. Rassinger, M. E. Pucher et al., "The impact of chromatin remodelling on cellulase expression in Trichoderma reesei," BMC Genomics, vol. 16, no. 1, p. 588, 2015.

[127] G. P. Borin, C. C. Sanchez, A. P. de Souza et al., "Comparative secretome analysis of Trichoderma reesei and Aspergillus Niger during growth on sugarcane biomass," PLoS One, vol. 10, no. 6, article e0129275, 2015.

[128] R. Peterson and H. Nevalainen, "Trichoderma reesei RUTC30-thirty years of strain improvement," Microbiology, vol. 158, no. 1, pp. 58-68, 2012.

[129] R. K. Aghcheh and C. P. Kubicek, "Epigenetics as an emerging tool for improvement of fungal strains used in biotechnology," Applied Microbiology and Biotechnology, vol. 99, no. 15, pp. 6167-6181, 2015.

[130] A. B. Sanz, R. García, J. M. Rodríguez-Peña, C. Nombela, and J. Arroyo, "Cooperation between SAGA and SWI/SNF complexes is required for efficient transcriptional responses regulated by the yeast MAPK Slt2," Nucleic Acids Research, vol. 44, pp. 7159-7172, 2016.

[131] R. M. Duran, S. Gregersen, T. D. Smith et al., "The role of Aspergillus flavus veA in the production of extracellular proteins during growth on starch substrates," Applied Microbiology and Biotechnology, vol. 98, no. 11, pp. 5081-5094, 2014.

[132] J. Schumacher, A. Simon, K. C. Cohrs et al., "The VELVET complex in the gray mold fungus Botrytis cinerea: impact of BcLAE1 on differentiation, secondary metabolism, and virulence," Molecular Plant-Microbe Interactions, vol. 28, no. 6, pp. 659-674, 2015.

[133] N. Trushina, M. Levin, P. K. Mukherjee, and B. A. Horwitz, "PacC and $\mathrm{pH}$-dependent transcriptome of the mycotrophic fungus Trichoderma virens," BMC Genomics, vol. 14, no. 1, p. 138, 2013.

[134] F. Castellanos, M. Schmoll, P. Martínez et al., "Crucial factors of the light perception machinery and their impact on growth and cellulase gene transcription in Trichoderma reesei," Fungal Genetics and Biology, vol. 47, no. 5, pp. 468476, 2010.

[135] M. Schmoll, L. Franchi, and C. P. Kubicek, "Envoy, a PAS/ LOV domain protein of Hypocrea jecorina (Anamorph Trichoderma reesei), modulates cellulase gene transcription in response to light," Eukaryotic Cell, vol. 4, no. 12, pp. 1998-2007, 2005.

[136] W. Dong, Q. Yinbo, and G. Peiji, "Regulation of cellulase synthesis in mycelial fungi: participation of ATP and cyclic AMP,” Biotechnology Letters, vol. 17, no. 6, pp. 593-598, 1995.

[137] G. P. Borin, C. C. Sanchez, E. S. de Santana et al., "Comparative transcriptome analysis reveals different strategies for degradation of steam-exploded sugarcane bagasse by Aspergillus niger and Trichoderma reesei," BMC Genomics, vol. 18, no. 1, p. 501, 2017.

[138] J. S. Bak, "Lignocellulose depolymerization occurs via an environmentally adapted metabolic cascades in the woodrotting basidiomycete Phanerochaete chrysosporium," Microbiology, vol. 4, no. 1, pp. 151-166, 2015.

[139] G. R. Hemsworth, E. M. Johnston, G. J. Davies, and P. H. Walton, "Lytic polysaccharide monooxygenases in biomass conversion," Trends in Biotechnology, vol. 33, no. 12, pp. 747-761, 2015.

[140] W. C. Kim, J. Y. Kim, J. H. Ko, H. Kang, and K. H. Han, "Identification of direct targets of transcription factor MYB46 provides insights into the transcriptional regulation of secondary wall biosynthesis," Plant Molecular Biology, vol. 85, no. 6, pp. 589-599, 2014.

[141] Y. Xiong, V. W. Wu, A. Lubbe et al., "A fungal transcription factor essential for starch degradation affects integration of carbon and nitrogen metabolism," PLoS Genetics, vol. 13, no. 5, article e1006737, 2017.

[142] S. T. Coradetti, J. P. Craig, Y. Xiong, T. Shock, C. Tian, and N. L. Glass, "Conserved and essential transcription factors for cellulase gene expression in ascomycete fungi," Proceedings of the National Academy of Sciences, vol. 109, no. 19, pp. 7397-7402, 2012.

[143] P. K. Foreman, D. Brown, L. Dankmeyer et al., “Transcriptional regulation of biomass-degrading enzymes in the filamentous fungus Trichoderma reesei," The Journal of Biological Chemistry, vol. 278, no. 34, pp. 31988-31997, 2003.

[144] F. Segato, A. R. Damásio, R. C. de Lucas, F. M. Squina, and R. A. Prade, "Genomics review of holocellulose deconstruction by aspergilli," Microbiology and Molecular Biology Reviews, vol. 78, no. 4, pp. 588-613, 2014.

[145] C. M. Payne, B. C. Knott, H. B. Mayes et al., "Fungal cellulases," Chemical Reviews, vol. 115, no. 3, pp. 1308-1448, 2015.

[146] A. Berlin, "No barriers to cellulose breakdown," Science, vol. 342 , no. 6165 , pp. 1454-1456, 2013. 


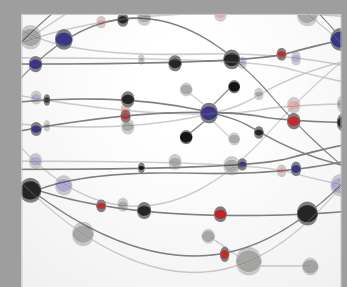

The Scientific World Journal
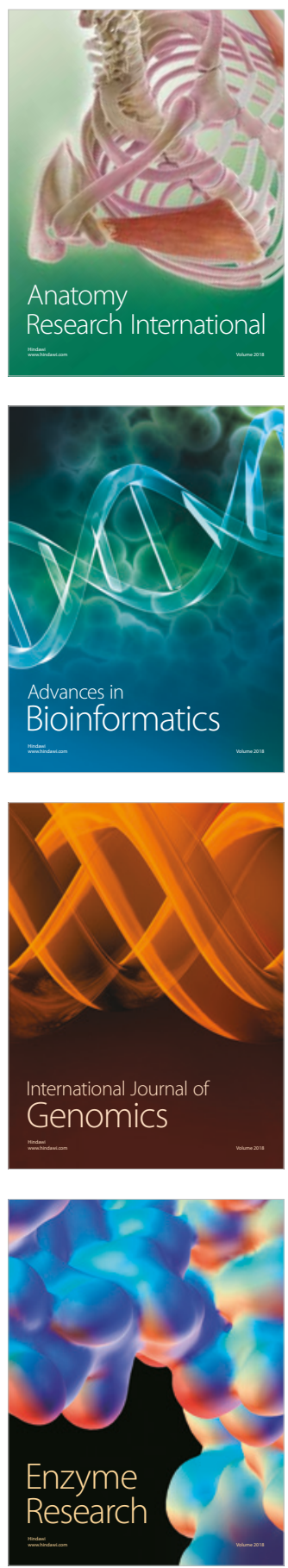
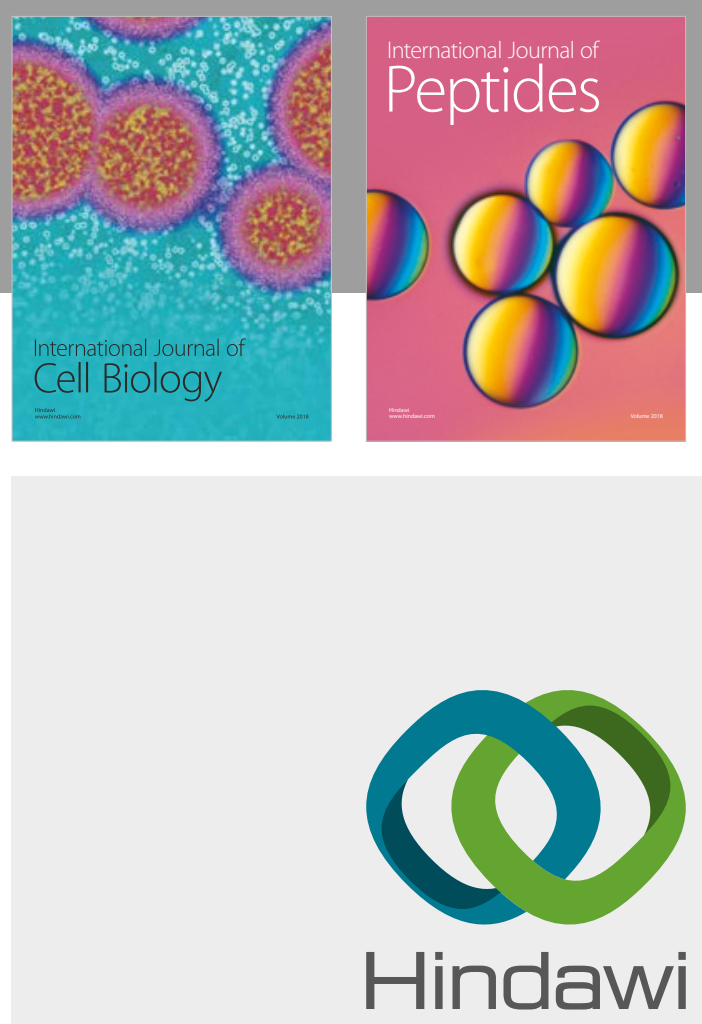

Submit your manuscripts at

www.hindawi.com
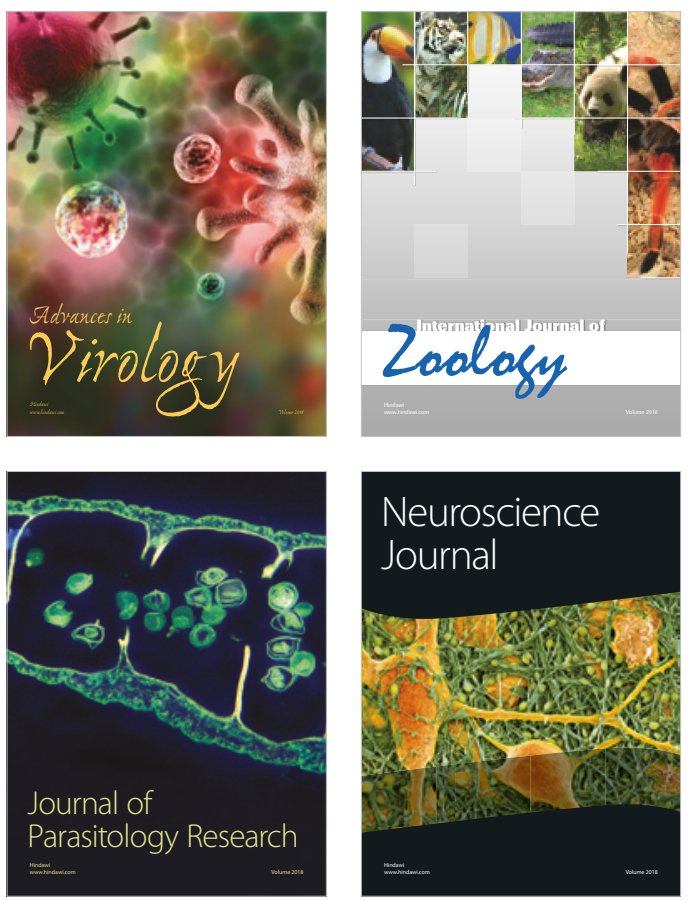
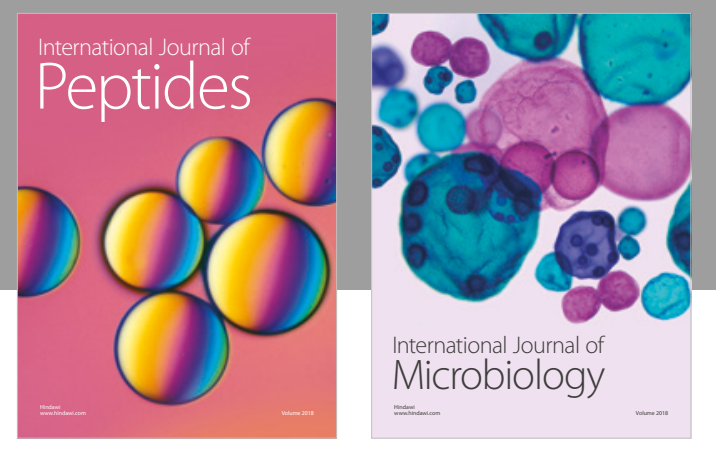

nternational Journal of Microbiology
Journal of
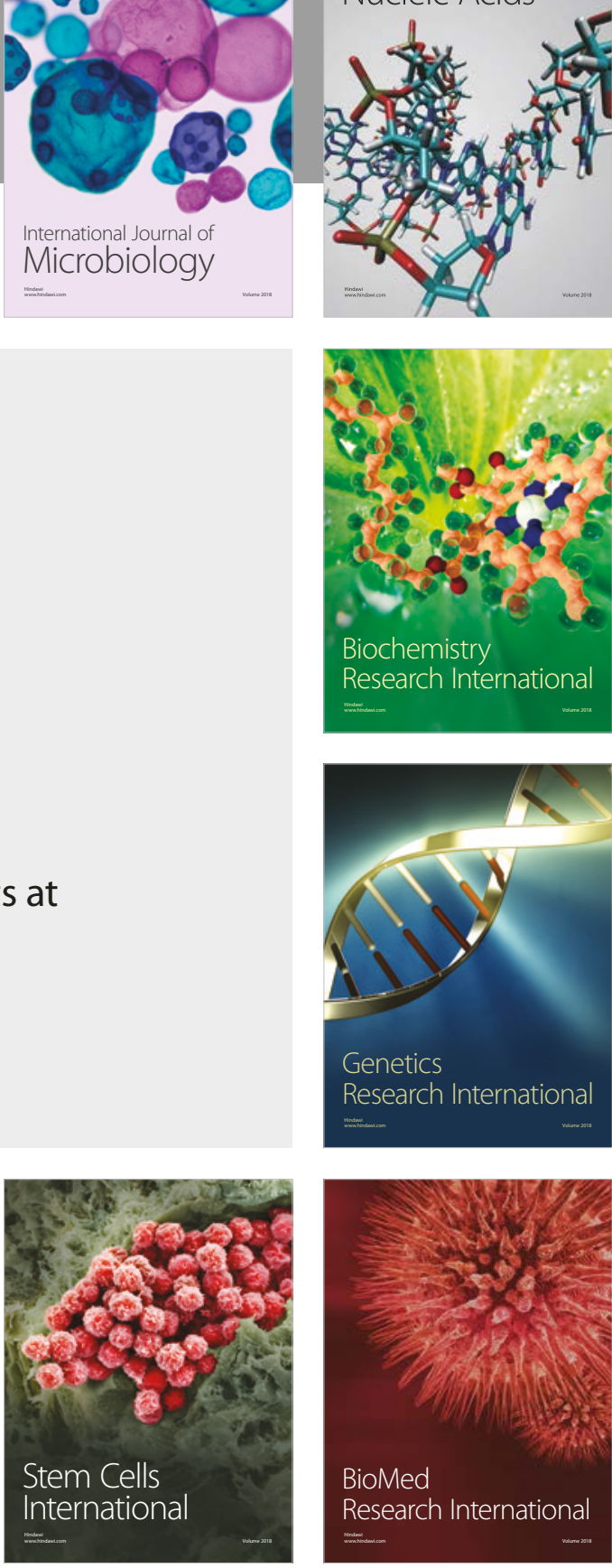
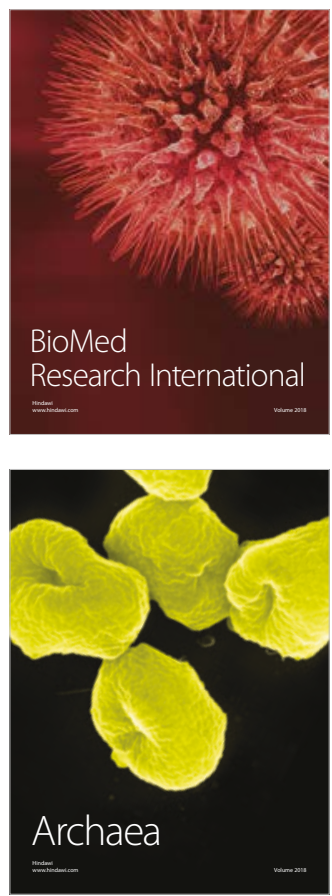